$$
\text { UNIVERSIDADE DE SÃO PAULO }
$$

Faculdade de Odontologia de Ribeirão Preto

\title{
EFEITO DA ADIÇÃO DE FIBRAS DE VIDRO \\ PARTICULADAS NAS PROPRIEDADES MECÂNICAS DE RESINAS ACRÍLICAS UTILIZADAS PARA A CONFECÇÃO DE PLACAS OCLUSAIS
}

Rodrigo Gonçalves Soares

Ribeirão Preto 2010 



$$
\text { UNIVERSIDADE DE SÃO PAULO }
$$

Faculdade de Odontologia de Ribeirão Preto

\title{
EFEITO DA ADIÇÃO DE FIBRAS DE VIDRO
}

\section{PARTICULADAS NAS PROPRIEDADES MECÂNICAS DE RESINAS ACRÍLICAS UTILIZADAS PARA A CONFECÇÃO DE PLACAS OCLUSAIS}

Rodrigo Gonçalves Soares

Orientador: Prof. Dr. Marcelo Oliveira Mazzetto

\begin{abstract}
Dissertação apresentada à Faculdade de Odontologia de Ribeirão Preto da Universidade de São Paulo, como parte dos requisitos necessários para obtenção do título de Mestre em Odontologia Restauradora área de Concentração - Dentística
\end{abstract}

Ribeirão Preto 
Autorizo a reprodução e divulgação total ou parcial deste trabalho, por qualquer meio convencional ou eletrônico, para fins de estudo e pesquisa, desde que citada à fonte.

Soares, Rodrigo Gonçalves

Efeito da adição de fibras de vidro particuladas nas propriedades mecanicas de resinas acrilicas utilizadas para a confecção de placas oclusais, 2010.

88 p. : Il.; $28 \mathrm{~cm}$

Orientador: Mazzetto, Marcelo Oliveira.

Dissertação apresentada à Faculdade de Odontologia de Ribeirão Preto da Universidade de São Paulo, como parte dos requisitos necessários para obtenção do título de Mestre. Odontologia Restauradora.

1. Placas oclusais 2. Resina acrílica 3. Fibra de vidro particulada 4. Rugosidade 5. Microdureza 6. Módulo de elasticidade 7 Resistência flexural. 
Nome do autor: RODRIGO GONÇALVES SOARES

TíTULO: EFEITO DA ADIÇÃO DE FIBRAS DE VIDRO PARTICULADAS NAS PROPRIEDADES MECÂNICAS DE RESINAS ACRÍLICAS UTILIZADAS PARA A CONFECÇÃO DE PLACAS OCLUSAIS

Dissertação apresentada à Faculdade de Odontologia de Ribeirão Preto da Universidade de São Paulo, como parte dos requisitos necessários para obtenção do título de Mestre.

Área de Concentração - Odontologia Restauradora

Aprovado em

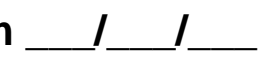

\section{BANCA EXAMINADORA}

1) $\operatorname{Prof}(a) . \operatorname{Dr}(a)$ :

Instituição: Assinatura:

2) $\operatorname{Prof}(a) . \operatorname{Dr}(a) .:$

Instituição: Assinatura:

3) $\operatorname{Prof}(a) . \operatorname{Dr}(a) .:$ Instituição: Assinatura: 
"Nunca se afaste dos seus sonhos, pois se eles se forem, você continuará vivendo, mas terá deixado de existir"

\section{Charles Chaplin}




\section{DeDicATÓRIA}

À Deu Deus, permanente luz do meu caminho.

Aos meus pais, Luzia e Florindo, exemplos de carinho e

Renúncia a favor dos filhos, que foram e ainda o são peça chave de Minha formação.

Acreditaram, contribuíram e compartilharam

Com a idealização de meus sonhos, sem permitir que nada me faltasse.

Ao meu irmão, Rogério, companheiro de perseverança

E busca por realizações pessoais. $O$ fato de ser meu irmão

já basta para os meus motivos de orgulho e alegria.

À minha cunhada, Regiane, e meu sobrinho, Felipe. A presença de vocês

foi constante em meus pensamentos.

O afeto e a disponibilidade de vocês me alimenta de um sentimento de gratidão imensurável.

Fazemos juntos, parte de um todo, e é a vocês que dedico este Trabalho. 
A Prof. Dr. Marcelo Oliveira Mazzetto, Certa vez, uma pessoa, talvez incomodada com a atenção e apoio que você me dispensava, chamou-me de “filho do Mazzetto".

Devo admitir que as cobranças e também o incentivo, fazem mesmo parte do papel de pai. Portanto, o que você tem feito por mim nos últimos anos foi muito próximo do papel de um pai que soube acolher um filho desamparado.

Obrigado por tudo.

À Profa. Dra. Andréa Cândido dos Reis pela atenção, campanhia e ensinamentos. Agradeço com veemência a sua ajuda e amizade.

À Dra. Camila Tirapelli pela amizade, companhia, ensinamentos e confiança. Agradeço com veemência a sua ajuda e amizade.

Ao amigo Dr. André Luis Botelho, por ter colaborando em parte da execução desse trabalho. A você, minha profunda gratidão, amizade e carinho.

Ao amigo Dr. Fabrício Mariano Mundim pela amizade, companheirismo e por ter colaborado em parte da execução deste trabalho. 


\section{AGRADECIMENTOS}

A todos os professores da FORP- USP. Especialmente aos do Departamento de Odontologia Restauradora. Muitíssimo obrigado pela disponibilidade, amizade e principalmente pela imprescindível contribuição na minha formação.

À minha família em Jaboticabal - SP, pela referência de uma vida simples e consistente.

A todos os funcionários da FORP- USP. Especialmente aos Srs. Edson, Ricardo, Francisco, pela dedicação que sempre prontamente me atenderam.

Aos meus colegas e amigos de Curso de Pós-Graduação. Muito obrigado pelo convívio e por poder aprender com vocês.

As pessoas amigas como André Luis Botelho, Fabrício Mariano Mundim, Ana Paula Farina, Doglas Cecchin, Daniel Galafassi. Obrigado por terem participado desta etapa da minha vida e por amenizarem o fenômeno "saudade de casa". A vocês, minha profunda gratidão e amizade.

Aos alunos de graduação da FORP-USP, com quem pude aprender durante a realização do Programa de Aperfeiçoamento de Ensino - PAE.

A Faculdade de Odontologia de Ribeirão Preto da Universidade de São Paulo, FORP- USP. Por ter me recebido na graduação e pós-graduação. 
Muito obrigado por possibilitar a mim e a demais brasileiros uma formação profissional sólida e de qualidade.

A Capes, pelo apoio financeiro tornando exeqüível este trabalho. Muito obrigado ainda a todas as pessoas que tenham auxiliado direta ou indiretamente este projeto.

Meus sinceros agradecimentos. 


\section{Resumo}

Placas oclusais são dispositivos intraorais utilizados no manejo de pacientes que apresentam desordens do sono, migrânia do tipo tensional e outros. No entanto são os cirurgiões dentistas que predominantemente utilizam as placas oclusais como tratamento do equilíbrio das arcadas dentárias nas disfunções temporomandibulares, prevenção de desgaste dental em pacientes com hábitos parafuncionais e na prevenção de traumas em atletas. Vários métodos têm sido empregados para reforçar resinas acrílicas, como reforço metálico e atualmente a incorporação de diferentes tipos de fibras tais como: carbono, polietileno e vidro. Contudo a adição de fibras de vidro com partículas menores em algumas propriedades mecânicas ainda permanecem desconhecidas.

Objetivo: O objetivo desse estudo foi avaliar algumas propriedades mecânicas como a rugosidade de superfície, microdureza, módulo de elasticidade e resistência flexural em resinas acrílicas após a incorporação de fibras de vidro particuladas pré silanizadas.

Material e método: Para avaliação das propriedades foram confeccionados vinte e quatro corpos de prova $(65 \times 10 \times 3 \mathrm{~mm})$ de cada marca comercial de resina acrílica, utilizadas para confecção de placas oclusais, Vipi Flash (autopolimerizável), Vipi Wave (termopolimerizável por calor de microondas), Vipi Crill, Lucitone e QC-20 (termopolimerizáveis por calor de banho de água), sendo doze corpos-de-prova controles, e doze experimentais, com adição de $10 \%$ em peso de fibras de vidro particuladas (Reforplás S/A, São Paulo, SP, Brasil). Após a realização do acabamento superficial dos corpos de prova com lixas de carborundum e feltros era realizada a avaliação da rugosidade superficial em rugosímetro (Mitutoyo®) com três leituras ao longo dos corposde-prova, a microdureza Vickers era analisada em um microdurômetro (Micro Hardness Tester, Shimadzu, Japan) com cinco mensurações em cada corpode-prova, e para avaliar os ensaios de resistência flexural e módulo de elasticidade os corpos-de-prova foram avaliados por meio uma máquina de ensaios universal (Emic DL 2000®, Emic, São José dos Pinhais, PR, Brasil), com velocidade de $5 \mathrm{~mm} / \mathrm{min}$. Os dados foram analisados estatisticamente, usando testes paramétricos e não paramétricos, de acordo com a distribuição da amostra.

Resultados: As médias e desvios padrões do teste de rugosidade superficial em Ra foram Vipi Flash sem fibra $(0,10 \pm 0,03)$; Vipi Flash com fibra $(0,12 \pm$ 
$0,01)$; Vipi Wave sem fibra $(0,16 \pm 0,02)$; Vipi Wave com fibra $(0,13 \pm 0,02)$; Vipi Cril sem fibra $(0,12 \pm 0,03)$; Vipi Crill com fibra $(0,15 \pm 0,03)$; Lucitone sem fibra $(0,10 \pm 0,02)$; Lucitone com fibra $(0,09 \pm 0,04)$; QC-20 sem fibra $(0,11 \pm 0,02)$ e QC-20 com fibra $(0,18 \pm 0,03)$.

As médias e desvios-padrão ao teste de microdureza Knoop com relação às marcas comerciais foram: Vipi Flash sem fibra $(15,35 \pm 0,3)$; Vipi Flash com fibra $(15,51 \pm 0,4)$; Vipi Wave sem fibra $(16,60 \pm 0,8)$; Vipi Wave com fibra $(17,25 \pm 0,9)$; Vipi Cril sem fibra (17,78 $\pm 2,27)$; Vipi Crill com fibra (18,02 $\pm 1,0)$; Lucitone sem fibra (15,72 $\pm 0,3)$; Lucitone com fibra $(16,69 \pm 0,6)$; QC-20 sem fibra $(15,91 \pm 0,4)$ e QC-20 com fibra $(15,63 \pm 0,2)$.

As médias e desvios-padrão ao teste de módulo de elasticidade foram: Vipi Flash sem fibra $(2952,76 \pm 292,12)$; Vipi Flash com fibra $(3373,49 \pm 403,76)$; Vipi Wave sem fibra $(2511,69 \pm 304,09)$; Vipi Wave com fibra $(3225,01 \pm$ 248,66); Vipi Cril sem fibra (2745,61 $\pm 288,86)$; Vipi Crill com fibra $(3671,67 \pm$ $329,91)$; Lucitone sem fibra $(1904,53 \pm 149,05)$; Lucitone com fibra $(3056,87 \pm$ 126,11); QC-20 sem fibra $(1913,86 \pm 147,80)$ e QC-20 com fibra $(2858,32 \pm$ $185,26)$. As médias e desvios-padrão ao teste de resistência flexural foram Vipi Flash sem fibra $(81,62 \pm 4,82)$; Vipi Flash com fibra $(83,98 \pm 4,98)$; Vipi Wave sem fibra (83,52 $\pm 8,79)$; Vipi Wave com fibra $(88,98 \pm 8,47)$; Vipi Cril sem fibra $(64,17 \pm 5,46)$; Vipi Crill com fibra $(93,37 \pm 9,97)$; Lucitone sem fibra $(74,71 \pm$ $9,43)$; Lucitone com fibra $(87,29 \pm 4,73)$; QC-20 sem fibra $(75,80 \pm 8,82)$ e QC20 com fibra $(81,67 \pm 12,97)$.

Conclusão: Conclui-se que a incorporação de fibras provocou alterações em praticamente todas as propriedades analisadas, sendo, portanto facilmente utilizável como um reforço adicional às resinas acrílicas. Com relação à dureza superficial as resinas acrílicas termopolimerizável por banho de água e termopolimerizável por calor de microondas apresentaram maiores valores quando comparados com a resina acrílica autopolimerizável. Além disso, a adição de fibras de vidro particuladas aumentou os valores de rugosidade de algumas resinas acrílicas Vipi Crill, Vipi Flash e Vipi Wave e se manteve constante nas resinas Lucitone e QC-20. A adição de fibra de vidro não aumentou significantemente a microdureza Knoop nos grupos em estudo. Com relação à resistência flexural as fibras de vidro particuladas aumentaram significantemente todos os valores, assim como o módulo de elasticidade das resinas acrílicas reforçadas pela adição de fibras de vidro. 


\begin{abstract}
Intraoral Occlusal splints are devices used in the management of patients with sleep disorders, migraine type tension and others. But dentists who are predominantly using the plates as a treatment of occlusal balance of the dental arches in temporomandibular disorders, prevention of tooth wear in patients with habits and prevention of injuries in athletes. Several methods have been used to strengthen acrylic resins, such as metal reinforcement and are currently incorporating different types of fibers such as carbon, polyethylene and glass. However the addition of glass fibers with smaller particles on mechanical properties are still unknown.
\end{abstract}

Objective: The objective of this study was to evaluate some mechanical properties such as surface roughness, hardness, elastic modulus and flexural strength in acrylic resins after the incorporation of glass fiber particulate pre silanized.

Methods: To evaluate the properties were made twenty-four specimens (65 x 10 $x 3 \mathrm{~mm}$ ) of each brand of acrylic resin, used for fabrication of occlusal splints, Vipi Flash (self-curing), Vipi Wave (by thermo microwave heat), Vipi CRILL, Lucitone and QC-20 (thermo heat water bath), with twelve specimes controls, and twelve experimental, with the addition of $10 \mathrm{wt} \%$ glass fiber particulate (Reforplás S / A, São Paulo, Brazil).

After completion of the roughness of the specimens with grit carborundum and felt it was evaluated the surface roughness on roughness tester (Mitutoyo $\AA$ ) with three readings over the specimes, the microhardness was examined with a hardness ( Micro Hardness Tester, Shimadzu, Japan) with five measurements in each specime, and evaluate the tests for flexural strength and modulus of elasticity of the specimes was evaluated using a universal testing machine (Emic DL 2000 ®, Emic, São José dos Pinhais, PR, Brazil), with speed $5 \mathrm{~mm} / \mathrm{min}$. The data were statistically analyzed using parametric and nonparametric tests, according to the sample distribution.

Results: The mean and standard deviation of the test surface roughness were Vipi Flash without fiber $(0.10 \pm 0.03)$; Flash Vipi with fiber $(0.12 \pm 0.01)$; Vipi Wave without fiber $(0,16 \pm 0.02)$; Vipi Wave with fiber $(0.13 \pm 0.02)$; Vipi Cril 
without fiber ( $0.12 \pm 0.03$ ); Vipi CRILL with fiber ( $0.15 \pm 0.03$ ); Lucitone without fiber ( $0.10 \pm 0.02)$; Lucitone with fiber $(0.09 \pm 0.04)$, QC-20 fiber without $(0.11 \pm$ $0.02)$ and QC-20 with fiber $(0.18 \pm 0.03)$. Means and standard deviations for Knoop microhardness test with respect to trademarks were Vipi Flash without fiber (15.35 \pm 0.3 ); Flash Vipi with fiber (15.51 \pm 0.4 ); Vipi Wave without fiber (16.60 \pm 0.8$)$; Vipi Wave with fiber (17.25 \pm 0.9$)$; Vipi Cril without fiber (17.78 \pm 2.27); Vipi CRILL with fiber (18.02 \pm 1.0 ); Lucitone without fiber (15.72 \pm 0.3 ); Lucitone with fiber (16.69 \pm 0.6$)$, QC-20 without fiber (15.91 \pm 0.4$)$ and QC-20 with fiber $(15,63 \pm 0.2)$. Means and standard deviations to test elastic modulus were Vipi Flash without fiber (2952.76 \pm 292.12$)$; Flash Vipi with fiber (3373.49 \pm 403.76); Vipi Wave without fiber (2511.69 \pm 304.09); Vipi Wave with fiber (3225.01 \pm 248.66$)$; Vipi Cril without fiber $(2745.61 \pm 288.86)$; Vipi CRILL with fiber (3671.67 \pm 329.91$)$; Lucitone without fiber (1904.53 \pm 149.05$)$; Lucitone with fiber (3056.87 \pm 126.11$)$, QC-20 without fiber (1913.86 \pm 147.80$)$ and QC20 with fiber (2858.32 \pm 18526$)$. Means and standard deviations for flexural strength were Vipi Flash without fiber (81.62 \pm 4.82 ); Flash Vipi with fiber (83.98 \pm 4.98 ); Vipi Wave without fiber (83.52 $\pm 8,79)$; Vipi Wave with fiber (88.98 \pm 8.47); Vipi Cril without fiber (64.17 \pm 5.46 ); Vipi CRILL with fiber (93.37 \pm 9.97$)$; Lucitone without fiber ( $74.71 \pm 9.43$ ); Lucitone with fiber (87.29 \pm 4.73 ), QC-20 without fiber (75.80 \pm 8.82$)$ and QC-20 with fiber $(81.67 \pm 12.97)$.

Conclusion: the conclusion is that the incorporation of fibers resulted in changes in almost all properties examined, and thus easily used as an additional reinforcement for acrylic resins. With respect to the surface roughness of acrylic resins by thermo water bath and microwave thermo heat showed higher values when compared with acrylic resin. Moreover, the addition of glass fiber particulate increased the roughness values of some acrylic resins Vipi CRILL, Vipi Flash and Vipi Wave and remained constant in the resins Lucitone and QC20. The addition of glass fiber does not increase significantly the microhardness in the groups. With respect to flexural strength glass fiber particulate significantly increased all values, as well as the modulus of acrylic resin reinforced by the addition of glass fibers. 


\section{SUMÁRIO}

\section{Resumo}

\section{Abstract}

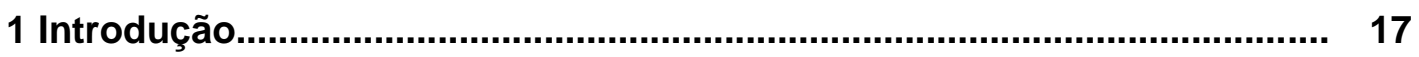

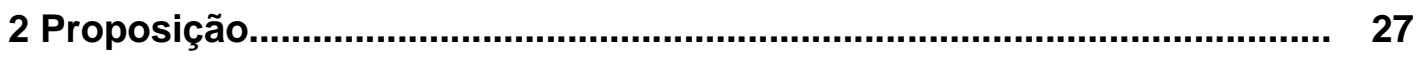

3 Material e Método............................................................................ 31

3.1Ensaio de Rugosidade Superficial.................................................... 37

3.2 Ensaio de microdureza Knoop.......................................................... 37

3.3 Ensaio de Módulo de Elasticidade e Resistência Flexural..................... 38

3.4 Módulo de Elasticidade .............................................................. 39

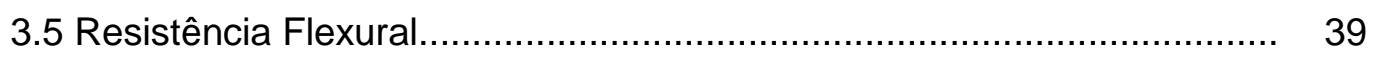

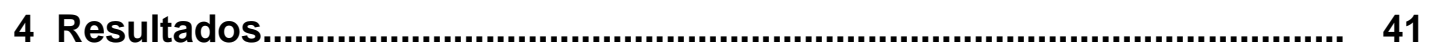

4.1 Rugosidade de superfície................................................................. 43

4.2 Microdureza Knoop................................................................. 44

4.3 Módulo de Elasticidade .................................................................. 46

4.4 Resistência Flexural ................................................................... 49

5 Discussão...................................................................................... 51

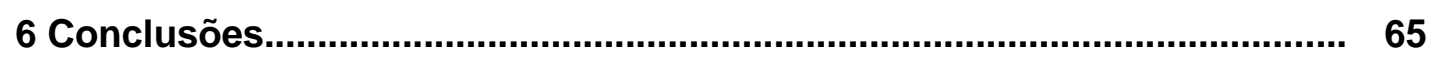

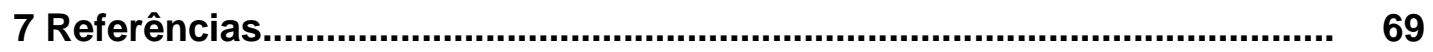

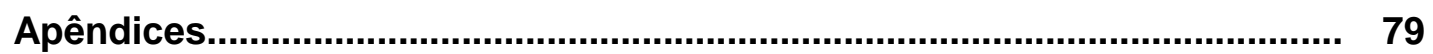





\section{Introdução}





\section{INTRODUÇÃo}

A desordem temporomandibular (DTM) é uma doença complexa e sua natureza não está completamente esclarecida (VISSER et al., 1995; LANDULPHO et al., 2004). O uso de placa oclusal é considerado uma forma efetiva no tratamento de disfunções temporomandibulares, uma vez que é uma terapia conservadora, não invasiva e reversível (DAO e LAVIGNE, 1998) para muitos pacientes que possuem hábitos parafuncionais (AMORIN et al., 2008).

Estes dispositivos intraorais estão indicadas para os mais variados tratamentos de diversas desordens, tais como: desordens do sono, migrânia do tipo tensional, Parkinson e apinéia (DAO, LAVIGNE, 1998). No entanto são os cirurgiões dentistas que predominantemente utilizam as placas oclusais para proteger os dentes de danos resultantes das forças de contração dos músculos mandibulares, para reduzir a dor orofacial pelo relaxamento dos músculos mastigatórios, como prevenção de desgaste dental em pacientes com bruxismo e em atletas (DAO, LAVIGNE, 1998), no entanto tais dispositivos devem possuir adequada resistência, resiliência e dureza (ANUSAVICE, 2003) e ser capaz de resistir às forças mastigatórias, força de impacto, e desgaste excessivo que podem ocorrer na cavidade oral, principalmente em pacientes que apresentam um quadro típico de hiperfunção.

O material mais comumente utilizado desde 1940 para a fabricação de próteses, confecção de dentes artificiais, base de dentaduras, selas de próteses parciais removíveis (O’BRIEN, 1997; ANUSAVICE, 2003) e placas oclusais (PAIVA E MAZZETTO, 2008) é o polimetil metacrilato (PMMA), uma resina acrílica. São materiais com excelentes propriedades estéticas, são de fácil 
processamento e fáceis de serem reparadas. Existem vários tipos de resinas acrílicas, como as termopolimerizáveis por banho de água e por calor de microondas, as fotopolimerizáveis e as autopolimerizáveis ou quimicamente ativadas (O’BRIEN, 1997; ANUSAVICE, 2003; PAIVA, MAZZETTO, 2008).

Pesquisadores da universidade de Milão na Itália desenvolveram uma placa oclusal que utiliza resinas acrílicas autopolimerizáveis denominada de (FARC) Functional Anatomy Research Center (FERRARIO; SFORZA; 1994; FERRARIO ET AL., 2002), esta placa se tornaria mais facilmente confeccionada, minimizando o tempo laboratorial e os custos. As resinas autopolimerizáveis têm como vantagem a fácil demuflagem, precisão dimensional e podem apresentar maior resistência flexural do que as termopolimerizáveis (ANUSAVICE, 2003). Como desvantagens podem apresentar fraturas com o tempo, possuem maior quantia de monômero residual em relação às termopolimerizáveis que acarretaria em porosidade interna e superficial decorrentes da volatilização do monômero, instabilidade de cor, reduzida rigidez e falha na adesão dental (O’BRIEN, 1996; ANUSAVICE, 2003), além da contração de polimerização e a indução de tensões que podem produzir alterações dimensionais e diminuição da resistência à fratura (ANUSAVICE, 2003).

Portanto um dos grandes inconveniente das resinas autopolimerizáveis é a presença do monômero residual que pode ser liberado na saliva e pode causar reações adversas tais como vermelhidão, inchaço e dor na mucosa oral. O monômero residual é proporcional ao tempo de cozimento de uma resina termopolimerizável, ou seja, quanto maior for o tempo de aquecimento menor a quantidade de monômero residual estará presente (BAYRAKTARA; DURANB; GUVENER, 2003). 
Para que uma resina sintética, seja utilizada na Odontologia, ela deve exibir qualidade excepcionais no que diz respeito a sua estabilidade química e dimensional. Além disso, ainda deve possuir propriedades que tornem o seu processamento relativamente fácil. A resina deve ser resistente, dura, mas não friável (ANUSAVICE, 2003). Muitos fatores afetam as propriedades das resinas acrílicas, incluindo a composição química da cadeia, o grau de polimerização e o número de ramificações e ligações cruzadas entre a cadeia polimérica. Os polímeros também se expandem devido à pequena absorção de água que normalmente ocorre (O’BRIEN, 1996). No geral, longas cadeias e alto peso molecular resultam no aumento da força, dureza, rigidez e resistência à fratura (UZUN; HERSEK; TINÇER, 1999) com um aumento na fragilidade das resinas acrílicas, o que pode limitar a sua utilização em situações de sobrecarga (VOJDANI, REZAEI, ZAREEIAN, 2008).

Por isso, reforços vêm sendo adicionados a este material na tentativa de torná-lo mais resistente em termos de propriedades mecânicas (KEYF; UZUN; MUTLU, 2003; VOJDANI, REZAEI, ZAREEIAN, 2008).

Dentre os materiais de reforço há pesquisas que utilizam a incorporação de metais às resinas, porém esse método é complexo e considerado de difícil manipulação (VALLITTU, LASSILA 1992; VALLITTU, 1993; VALLITTU, 1996; POLYZOIS, ANDREOPOULOS, LAGOUVARDOS, 1996; KANIE et al., 2000; VOJDANI, REZAEI, ZAREEIAN, 2008).

Segundo CHEN, LIANG, YEN, em 2001, a utilização de algum tipo de fibra parece ser a melhor alternativa uma vez que são materiais que apresentam elevada resistência. As estruturas de compósitos reforçados com fibras fornecem 
força e rigidez auxiliares às resinas acrílicas (KEYF, UZUN, MUTLU, 2003). Com isso há a combinação de força e rigidez das fibras com as propriedades particulares dos compósitos (resistência e estética) (FREILICH et al., 1998).

Em adição, o reforço com fibra tem vantagens em relação a outros métodos de reforço, incluindo melhora na estética, melhora na união a matriz resinosa, e fácil de reparar (KIM, WATTS, 2004).

Dentre as fibras pesquisadas, as principalmente utilizadas são as fibras de vidro, carbono, aramida e polietileno (VALLITTU, LASSILA, LAPPALAINEN, 1994; KIM, WATTS, 2004; TACIR et al., 2006; VOJDANI, REZAEI, ZAREEIAN, 2008; STIPHO, 2008). Tais fibras afetam as propriedades do compósito dependendo dos seguintes fatores: tipo da matriz, tipo da fibra, distribuição da fibra, proporção matriz/fibra, adesão das fibras à matriz polimérica (VALLITTU, 1999), diâmetro e comprimento da fibra, orientação da fibra, impregnação de fibra com a matriz polimérica e das propriedades das fibras x propriedades da matriz polimérica (SAMADZADEH et al., 1997; KEYF, UZUN, MUTLU, 2003).

As fibras de carbono não têm um efeito irritante e melhoram muito a resistência ao impacto, resistência à fadiga, resistência transversa e à deflexão assim como o módulo de elasticidade, isso tudo por um baixo custo (KEYF; UZUN; MUTLU, 2003), porém são dificilmente utilizadas por sua pobre estética (UZUN, HERSEK, TINÇER, 1999; KANIE et al., 2000; KEYF; UZUN; MUTLU, 2003; VOJDANI, REZAEI, ZAREEIAN, 2008), fibras do tipo Kevlar (aramida) têm rigidez elevada, são resistentes ao manchamento (O’BRIEN, 1996), porém desapontam esteticamente (KEYF; UZUN; MUTLU, 2003; VOJDANI, REZAEI, ZAREEIAN, 2008) e são difíceis de trabalhar (O’BRIEN, 1996). Ao contrário das fibras de carbono e as fibras de Kevlar, fibra de polietileno são quase invisíveis 
em resinas acrílicas (UZUN, HERSEK, TINÇER, 1999), porém o processo de presa, preparo e posicionamento das fibras pode ser impraticável para o laboratório de prótese (VOJDANI, REZAEI, ZAREEIAN, 2008), levando desta forma a uma imprópria adesão entre as fibras de polietileno e a matriz polimérica, o que tem limitado o seu uso (KEYF, UZUN, MUTLU, 2003).

Atualmente um dos principais materiais utilizados como reforço são as fibras de vidro (KEYF; UZUN; MUTLU, 2003), pois apresentam elevadas propriedades mecânicas, são estéticas, estabilidade no meio ambiente oral e biocompatíveis (ANUSAVICE, 2003). As fibras de vidro estão disponíveis na forma contínua, unidirecional, tecido, malha e pó (particulada), são virtualmente invisíveis quando incorporadas ao PMMA (KANIE et al., 2000). Fibra de vidro silanizada é um material promissor devido à sua boa adesão a matriz polimérica, elevada qualidade estética (VALLITTU; RUYTER; EKSTRAND, 1998), e aumento da resistência dos compósitos (VOJDANI, REZAEI, ZAREEIAN, 2008), além de biocompatibilidade.

As fibras de vidro particuladas e pré silanizadas são facilmente incorporadas ao polímero das resinas acrílicas e desta forma próteses ou placas oclusais podem então ser construídas exatamente da mesma forma que elas seriam normalmente (FRANKLIN, WOOD, BUBB, 2005). Segundo CZIGÁNY, NÉMETH, ELINGER, em 2001, quanto mais finas são as fibras maior a probabilidade de melhor distribuição por todo o corpo da resina, tornando desta forma o material mais resistente à deformação.

Portanto para analisar tais fibras foram propostos vários ensaios mecânicos para se certificar que melhoram significantemente as propriedades das resinas acrílicas e assim possam ser facilmente incorporadas às mesmas. Para tanto foi 
proposta a analise da rugosidade superficial uma vez que quando devidamente utilizadas às placas oclusais acabam sendo desgastadas pelo paciente tornandoa mais rugosa e muitas vezes formando trincas por toda a placa oclusal. Há na literatura muitos estudos mostrando que a adição de fibras aumenta a resistência do acrílico (VALLITTU, LASSILA, LAPPALAINEN, 1994; VALITTU, 1999; STIPHO, TALIC, 2001; KIM, WATTS, 2004; TACIR et al., 2006; VOJDANI, REZAEI, ZAREEIAN, 2008;), porém não há nada na literatura estudos com relação ao impacto das fibras sobre a rugosidade de superfície (ZORTUK, et al., 2008). A rugosidade superficial é amplamente investigada porque ela indica as características da polimerização, uma vez que resinas mal polimerizadas podem apresentar superfície irregular. A rugosidade de superfície de 0,30 mm pode ser sentida pela língua, tendo assim um impacto negativo no conforto do paciente (ZORTUK, et al., 2008). Estas irregularidades na superfície são áreas de depósitos ideais para a colonização de microorganismos, porque a retenção ocorre preferencialmente em superfícies ásperas, pois fornecem proteção contra forças de cisalhamento, que seriam capazes de remover tais microorganismos (SOUZA JUNIOR, et al., 2006). Assim, quando há um aumento na rugosidade superficial pode resultar em um aumento de acúmulo de biofilme (BOLLEN, LAMBRECHTS, QUIRYNEN, 1997; SOUZA JUNIOR, et al., 2006). Estudos têm demonstrado que a diminuição da rugosidade em superfícies duras reduz a formação de placa (ZORTUK, et al., 2008) Porém, técnicas convencionais de polimento não são capazes de deixar as superfícies completamente lisas, facilitando o acúmulo de microorganismos, principalmente quando fibras são incorporadas (VERRAN, MARYAN, 1997). 
Uma propriedade importante a ser avaliada é a dureza superficial, pois esta propriedade pode simular um possível desgaste da placa em hábitos parafuncionais tais como o bruxismo, esta propriedade mede a resistência de um material à penetração de um dispositivo colocado sobre a superfície do mesmo por um determinado período de tempo, deixando uma impressão (indentação).

Outra propriedade importante para avaliar a resistência das placas oclusais é a utilização do módulo de elasticidade que representa a rigidez de um material e ele é avaliado pela curva da porção elástica de um gráfico tensão/deformação (ANUSAVICE, 2003). Segundo este mesmo autor, por meio deste teste pode-se estimar um possível desempenho clínico do material sob cargas mastigatórias, uma vez que o módulo de elasticidade avalia a rigidez necessária para fornecer conforto ao paciente durante a mastigação sem que este material seja fletido, o que levaria a uma situação de desconforto (DOGAN et al., 2008). Quanto menor for à deformação para uma dada tensão, maior será o valor do módulo de elasticidade. A magnitude do módulo de elasticidade é um fator de influência na intensidade dos estresses gerados durante 0 endurecimento da resina (ANUSAVICE, 2003).

O PMMA deve ter força suficiente e resiliência para não apenas suportar cargas mastigatórias normais, mas altas tensões súbitas (O’BRIEN, 1996) tais como as causadas pelo apertamento dental e/ou bruxismo.

A resistência flexural ou módulo de ruptura ou resistência transversa representa a resistência máxima ao dobramento de um material antes que ocorra fratura (DOGAN et al., 2008), é feito por meio de um teste de três pontos, que mede a tensão de tração/compressão e de cizalhamento de espécimes em forma de barras quando submetidos a uma carga (GAROUSHI, VALLITTU e LASSILA, 
2008). Na região superior há a tensão de compressão e na região inferior há a tensão de tração, ou também comumente denominada de alongamento (ANUSAVICE, 2003). Falha flexural dos materiais é considerada a principal falha clínica e tem sido explicada pelo desenvolvimento de trincas microscópicas em regiões de concentração de tensões (KANIE et al., 2000; DOGAN et al., 2008). A resistência depende da composição da resina, da técnica de processamento e do meio em que a resina ficará exposta (ANUSAVICE, 2003). Clinicamente, a fratura de próteses e/ou placas oclusais está relacionada com esforços mastigatórios excessivos, principalmente em pacientes que apresentem um hábito parafuncional como o bruxismo e/ou apertamento dental. 
2 Proposição 



\section{ProposiçÃo}

O objetivo desse estudo foi avaliar a incorporação de fibras de vidro particuladas e pré silanizadas nas resinas acrílicas, para verificar as alterações nas propriedades mecânicas através dos testes de microdureza, rugosidade de superfície, módulo de elasticidade e resistência flexural, quando comparadas com as resinas acrílicas convencionais utilizadas em placas oclusais. 

3 Material e Métodos 



\section{MATERIAL E MÉTOdOS}

Este estudo foi constituído por dez grupos com doze espécimes em cada grupo $(10 \times 12=120$ corpos de prova). Cinco destes grupos, controle, não possuíam reforço e os outros cinco grupos possuíam o reforço com fibra de vidro particuladas tratadas superficialmente por uma resina epóxica mais uma gente de união silano e com tamanho médio das partículas de 0,12 $\mu \mathrm{m}$ (Fig. 1). Para este estudo foi utilizada a proporção de $10 \%$ em peso de fibra de vidro (FREGONESI, 1985). As marcas comerciais e tipo de polimerização estão ilustradas na Tabela 1.

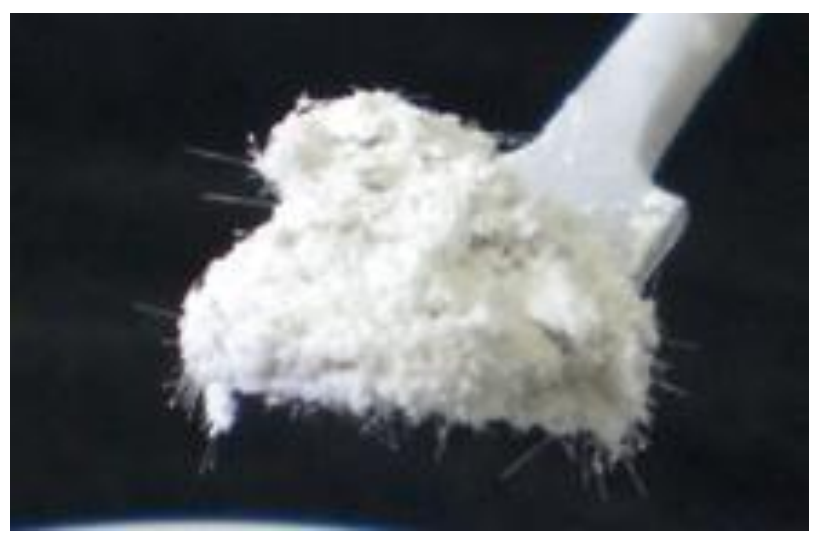

Figura 1 - Fibras de vidro.

Para os ensaios uma matriz de Teflon (Teflon DuPont, Wilmington, Del) foi construída com $67 \mathrm{~mm}, 12 \mathrm{~mm}$ e $3 \mathrm{~mm}$. As matrizes foram incluídas em gessopedra tipo III (Herodent/Vigodent, Rio de Janeiro, RJ, Brasil) espatulado manualmente e vazado no interior de uma mufla (Fig. 02 b), e foram aguardados 30 minutos para a presa do gesso, permanecendo o molde para a confecção dos corpos-de-prova de resina acrílica com as mesmas dimensões da matriz (Fig. 02 b e c ). 
Tabela 1 - As marcas comerciais e tipo de polimerização das resinas acrílicas

\begin{tabular}{ccc}
\hline Resinas & Nome/Fabricante & Polimerização \\
\hline Vipi Flash & Vipi, Pirassununga, SP, Brasil & Autopolimerizável \\
Vipi Wave & Vipi, Pirassununga, SP, Brasil & $\begin{array}{c}\text { Termopolimerizável por calor } \\
\text { de microondas }\end{array}$ \\
Vipi Crill & Vipi, Pirassununga, SP, Brasil & $\begin{array}{c}\text { Termopolimerizável por calor } \\
\text { de banho de água }\end{array}$ \\
Lucitone & Dentsply Intl, York, USA & $\begin{array}{c}\text { Termopolimerizável por calor } \\
\text { de banho de água }\end{array}$ \\
QC-20 & Dentsply Intl, York, USA & $\begin{array}{c}\text { Termopolimerizável por calor } \\
\text { de banho de água }\end{array}$ \\
\hline
\end{tabular}

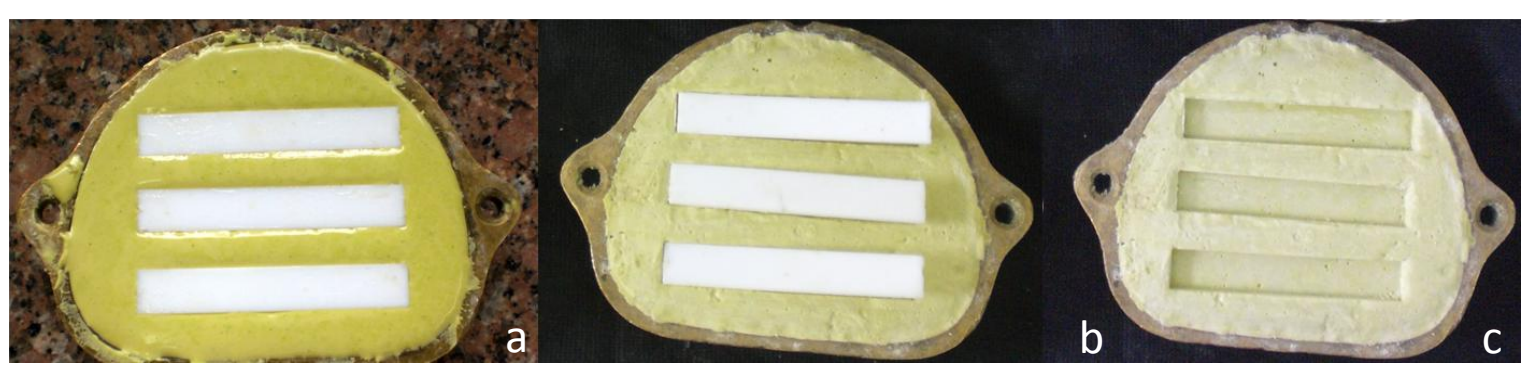

Figura 2 - a) matrizes de teflon incluídas no gesso; b e c) desinclusão das matrizes.

O pó (polímero) da resina (Fig. 3b) foi pesado em balança de precisão (Metter Toledo, Micronal S/A, São Paulo, SP, Brasil) (Fig. 03 a) assim como as partículas da fibra de vidro (Reforplás S.A, São Paulo, SP, Brasil) (Fig. 3 c), e o líquido (monômero) foi aspirado por meio de uma pipeta acoplado a um pipetador (Bel-art products, Spain). A proporção entre o polímero e o monômero não foi alterada e foram seguidas as recomendações do fabricante. 


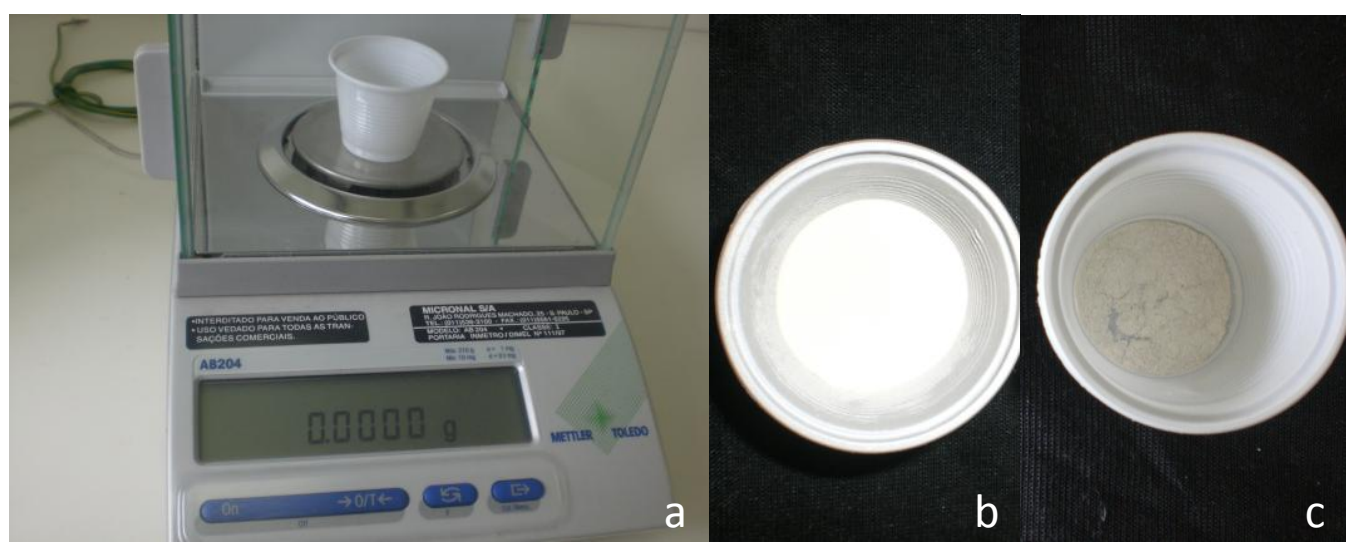

Figura 3 - Pesagem da resina acrílica e fibra de vidro; a) balança de precisão; b) polímero pesado c) fibra de vidro pesada.

Previamente à colocação da resina acrílica, a mufla era isolada por uma ligeira camada de isolante Cel Lac (SS White Artigos Dentários Ltda, Rio de Janeiro, Brasil) (Fig. 4 a). Em um pote de vidro com tampa o monômero foi despejado e sobre ele o pó foi dispensado, por meio de uma espátula $n^{0} 7$, e deste forma foram misturados até obtenção de uma mistura homogênia, até a saturação do conjunto. Após atingir a fase plástica a resina foi vertida sobre as marcações feitas pela matriz com ligeiro excesso para permitir que o escoamento fosse uniforme durante o procedimento de prensagem. A prensagem foi realizada por meio de uma prensa hidráulica (Midas Dental Products VH, Araraquara, SP, Brasil) (Fig. 4 b) de forma lenta e gradual, até se estabelecer uma pressão de $1000 \mathrm{KgF}$.

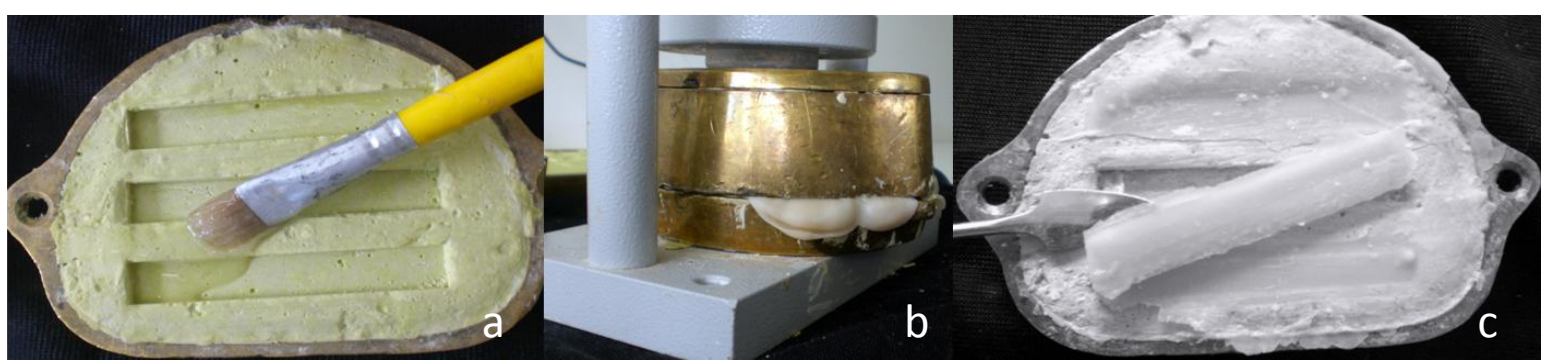

Figura 4 - a) isolamento da gesso; b) prensagem da mufla; c) desinclusão da resina acrílica. 
Para a resina termoativada por calor de microondas a mufla foi aparafusada e levada a um microondas (Panasonic, Manaus, AM, Brasil), já para as resinas termopolimerizável por banho de água e autopolimerizável procedeuse a prensagem manual a fim de manter a pressão e o íntimo contato entre as paredes durante o período de polimerização das resinas acrílicas. Para os procedimentos de polimerização as recomendações dos respectivos fabricantes foram seguidas criteriosamente.

Após o resfriamento da mufla os corpos-de-prova foram desincluídos (Fig. 4 c) e armazenados em água destilada, à temperatura ambiente. Posteriormente a demuflagem, os excessos de resina acrílica foram desgastados com o auxílio de uma broca de tungstênio Maxicut (Edenta AG, Switzerland) (Fig. 5 a e b). O polimento para todos os corpos de prova foi por meio de lixas de carborundum (Noroton, Indústria e Comercio Limitada, São Paulo-S.P., Brasil) nas granulações de 200, 500, 600, 800 e 1200, acopladas em uma lixadeira elétrica (Struers DPU10, Panambra, São Paulo, SP, Brasil) (Fig. 5 c) finalizando, com feltro e pasta alumina (Arotec, São Paulo, SP, Brasil) para o teste de microdureza Knoop.

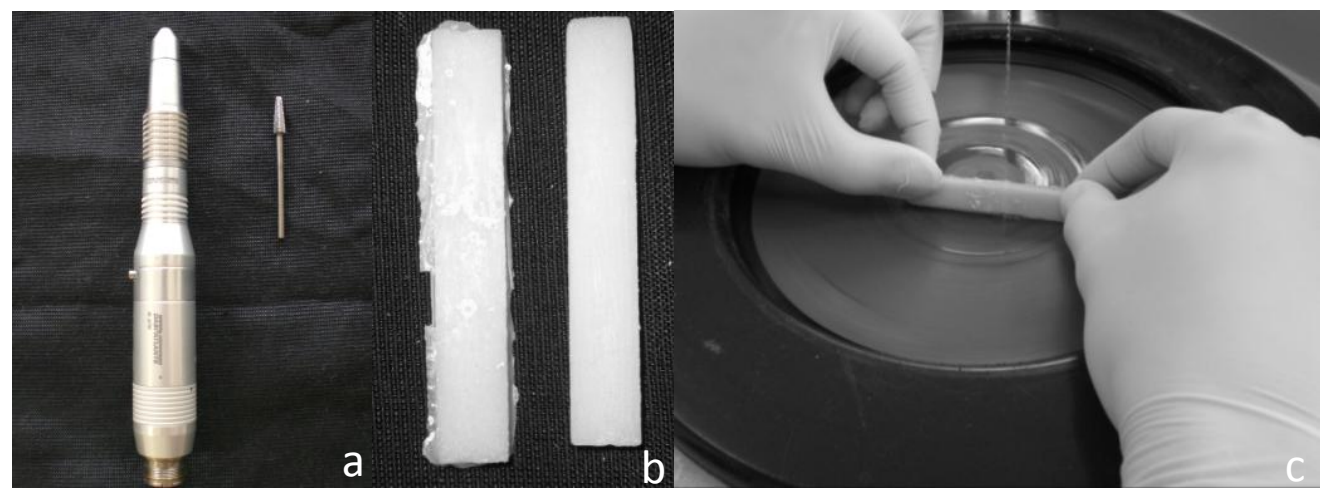

Figura 5 - Acabamento e polimento dos corpos de prova: a) micromotor e maxicut; b) a direita corpo de prova após acabamento; c) polimento com tiras de lixa. 
Os corpos-de-prova de prova em resina acrílica foram confeccionados de acordo com as especificações da "International Organization Standardization" (ISO) (ISO 10477:1992/Amd 1:1998) (Fig.6).

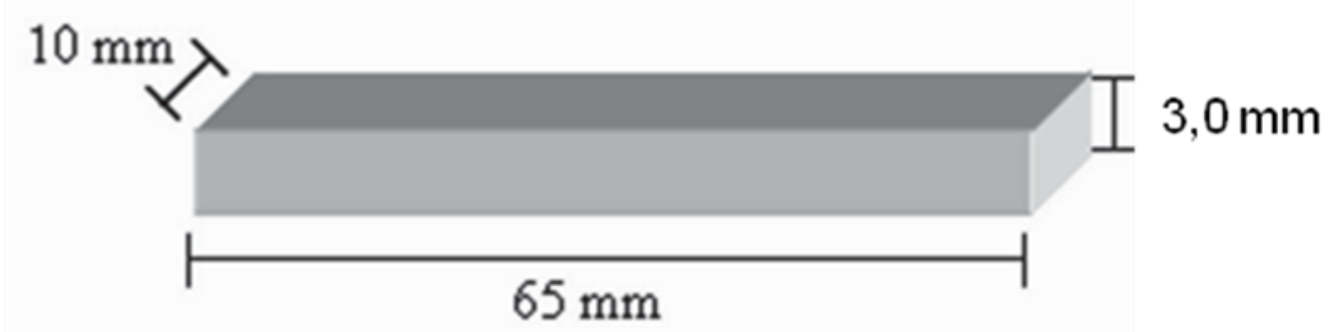

Figura 6 - Esquema do corpo-de-prova em resina acrílica.

\subsection{Ensaio de Rugosidade Superficial}

A rugosidade superficial mensurada em $\mu \mathrm{m}(\mathrm{Ra})$ foi analisada por meio de um aparelho Mitutoyo ${ }^{\circledR}$ (SJ - 201P, Japan), de alta sensibilidade, com ponta analisadora esférica de diamante, utilizada para medir a rugosidade superficial de forma quantitativa. A ponta analisadora percorre a superfície e por meio de um software processa e interage a informação. Três leituras ao longo dos corpos-deprova foram realizadas: uma central e as demais nas extremidades. $O$ valor da rugosidade utilizado foi à média aritmética das leituras.

\subsection{Ensaio de microdureza Knoop}

Para o ensaio de dureza Knoop foram utilizados doze corpos-de-prova para cada marca comercial de resina. As medidas de dureza Knoop foram efetuadas em um aparelho HMV (Micro Hardness Tester, Shimadzu, Japan) usando uma carga de 25 gramas por 30 segundos de tempo para cada penetração, num total 
de cinco penetrações para cada corpo-de-prova. Cada uma destas penetrações formava um losango (Fig. 7) a partir da mensuração de sua maior diagonal dada em mm, cujo valor é aplicado em uma fórmula matemática calculado automaticamente pelo microdurômetro para obtenção dos resultados da dureza Knoop, que era dado pela média dos valores das marcações medidas.

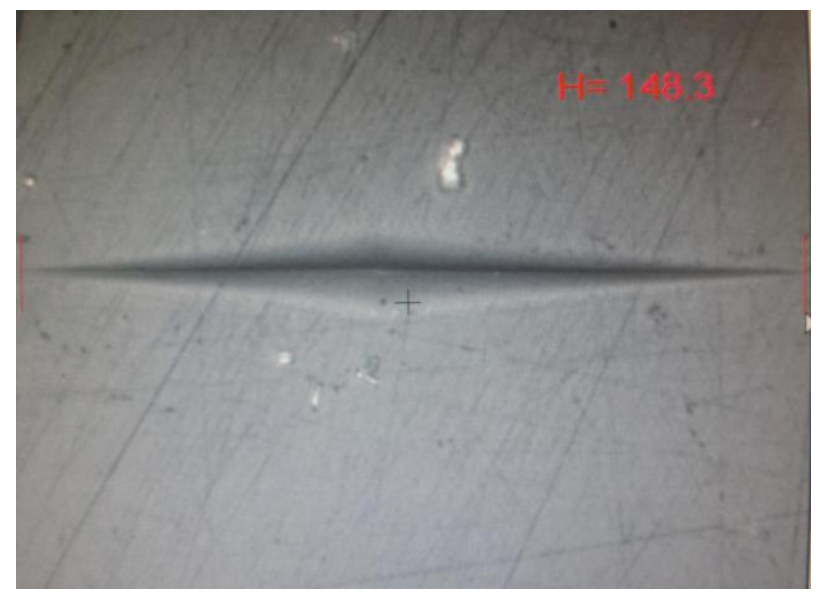

Figura 7 - representação da marcação feita pela ponta do microdurômetro.

\subsection{Ensaio de Módulo de Elasticidade e Resistência Flexural}

O ensaio mecânico para o registro da resistência flexural, módulo de elasticidade e carga de ruptura foi realizado por meio de do teste de carga de três pontos, em uma máquina de ensaio universal (Emic DL 2000®, Emic, São José dos Pinhais, PR, Brasil), com célula de carga de 200 N. Os corpos-de-prova eram posicionados na máquina (Fig. 8), com distância de $50 \mathrm{~mm}$ entre os apoios e velocidade de $5 \mathrm{~mm} / \mathrm{min}$, e flexionados até ocorrer a fratura. A máquina ligada a um computador passava as medidas dos valores em Kgf que foram convertidos em Newtons pela relação $1 \mathrm{~N}=9,81 \mathrm{Kgf}$. Estes valores em Newton é que seriam utilizados para o cálculo do módulo de elasticidade e resistência flexural. 


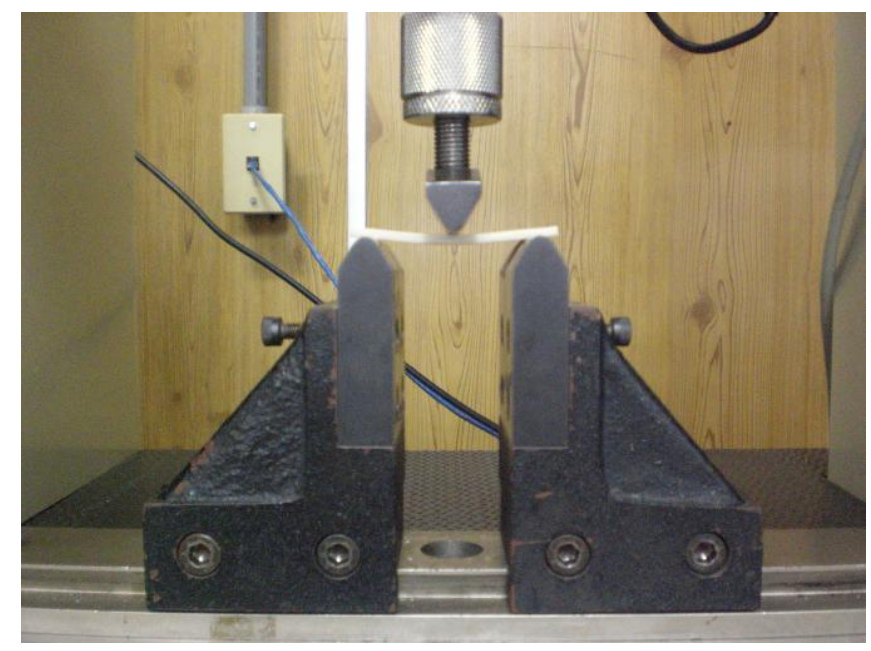

Figura 8 - Maquina de ensaios universais.

\subsection{Módulo de Elasticidade}

O módulo de elasticidade é calculado pela seguinte fórmula: $E=\boldsymbol{I}^{3} \boldsymbol{P} / \mathbf{4} \boldsymbol{F b h ^ { 3 }}$, em que $\boldsymbol{E}$ é o módulo de elasticidade em MPa (Mega Pascal), I é a distância entre os suportes, que era constante $50 \mathrm{~mm}, \boldsymbol{P}$ é a carga da deformação elástica em $\mathrm{N}$, $\boldsymbol{F}$ é a deflexão dos corpos-de-prova em milímetros, $\boldsymbol{b}$ é a largura dos corpos-deprova em milímetros, e $\boldsymbol{h}$ é a espessura dos corpos-de-prova em milímetros.

\subsection{Resistência Flexural}

A resistência flexural é calculada pela fórmula: $\mathbf{S}=\mathbf{3 P I} / \mathbf{2} \boldsymbol{b} \boldsymbol{d}^{2}$ onde: $\mathbf{S}=$ resistência à flexão ou resistência flexural ou módulo de ruptura $\left(\mathrm{N} / \mathrm{mm}^{2}\right), \mathbf{P}=$ Carga de fratura $(\mathrm{N}), \mathbf{I}=$ Distância entre os apoios $(\mathrm{mm}), \mathbf{b}=$ Largura do corpo-deprova $(\mathrm{mm}), \mathbf{d}=$ espessura do corpo-de-prova $(\mathrm{mm})$.

Os resultados obtidos foram submetidos ao teste de aderência curva normal. Para os dados que apresentaram distribuição normal foi utilizada a análise de variância (ANOVA) seguida do pós-teste de Tukey, quando apropriado. Para os dados que apresentaram distribuição não-normal foi utilizado o teste de Kruskal-Wallis seguido do pós-teste de Fischer, quando apropriado. O nível de significância foi estabelecido a $5 \%$ para ambos os testes estatísticos. 

4 Resultados 



\section{Resultados}

\subsection{Rugosidade de superfície}

A análise estatística (Kruskal-Wallis) evidenciou que houve diferença significante $(p<0,05)$ em relação ao fator marca comercial de resinas acrílicas (Tabela 1). O menor valor de rugosidade $(0,09 \mathrm{Ra})$ foi observado na resina Lucitone, enquanto o maior valor $(0,13 \mathrm{Ra})$ na resina Vipi Crill. A rugosidade superficial foi semelhante $(p>0,05)$ entre as resinas QC-20, Vipi Wave e Vipi Flash.

Tabela 1 - Resultado do teste de Kruskal-Wallis entre resinas: valores médios $(\mathrm{Ra})$ e desvios-padrões.

\begin{tabular}{cc}
\hline Resinas & Média ( \pm desvio padrão) \\
\hline Vipi Wave & $0.11( \pm 0.02)^{\mathrm{a}, \mathrm{b}}$ \\
Vipi Flash & $0.10( \pm 0.02)^{\mathrm{a}, \mathrm{c}}$ \\
Vipi Crill & $0.13( \pm 0.03)^{\mathrm{b}}$ \\
Lucitone & $0.09( \pm 0.03)^{\mathrm{c}}$ \\
QC-20 $^{\mathrm{a}}$ & $0.11( \pm 0.03)^{\mathrm{a}, \mathrm{c}}$ \\
\hline
\end{tabular}

A adição de fibras de vidro particuladas promoveu aumento estatisticamente significante $(p<0,05)$ na rugosidade superficial das resinas avaliadas (Tabela 2).

Tabela 2 - Valores médios (Ra) e desvios padrões dos corpos-de-prova com e sem fibras de vidro.

\begin{tabular}{cc}
\hline Reforço & Média ( \pm desvio padrão) \\
\hline Sem Fibra & $0.09( \pm 0.03)^{a}$ \\
Com Fibra & $0.11( \pm 0.04)^{b}$ \\
\hline${ }^{*}$ letras iguais indicam semelhança estatística
\end{tabular}


A análise estatística indicou a ocorrência de interação significante $(p<0,05)$ entre as resinas utilizadas e a adição de fibras de vidro. No gráfico 1, nota-se um aumento nos valores de rugosidade superficial quando foram incorporadas fibras de vidro nas resinas Vipi Flash, Vipi Crill, Vipi Wave, porém as resinas QC-20 e Lucitone exibiram valores semelhantes de rugosidade superficial (Ra) após adição de fibras de vidro particuladas.

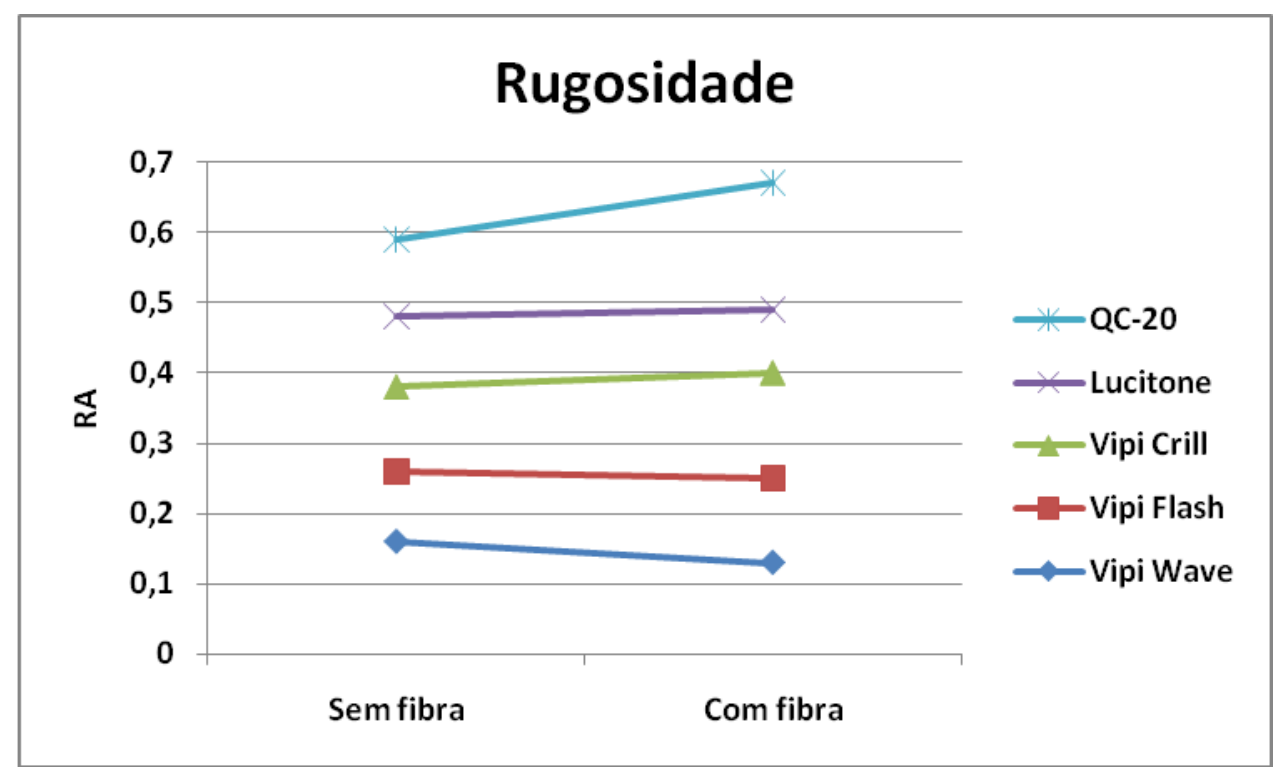

Grafico 1 - Rugosidade superfície após a incorporação das fibras de vidro particuladas.

\subsection{Microdureza Knoop}

A análise de variância (ANOVA-TWO WAY) indicou diferença estatísticamente significante entre as marcas comerciais de resinas $(p<0.05)$. A resina Vipi Crill presentou o maior valor de dureza Knoop (17.90 \pm 1.74$)$, enquanto a resina Vipi Flash exibiu o menor valor (15.44 £0.39) (Tabela 3). 
Tabela 3 - Dureza Knoop $\left(\mathrm{Kg} / \mathrm{mm}^{2}\right)$ - médias e desviospadrões

\begin{tabular}{cc}
\hline Resinas & Média ( \pm desvio padrão) \\
\hline Vipi Wave & $16.93( \pm 0.93)^{\mathrm{a}}$ \\
Vipi Flash & $15.44( \pm 0.39)^{\mathrm{b}}$ \\
Vipi Crill & $17.90( \pm 1.74)^{\mathrm{c}}$ \\
Lucitone & $16.21( \pm 0.69)^{\mathrm{ab}}$ \\
QC-20 & $15.78( \pm 0.39)^{\mathrm{AC}}$ \\
\hline
\end{tabular}

A adição de fibra de vidro não interferiu na microdureza das resinas avaliadas (Tabela 4)

Tabela 4 - Dureza Knoop $\left(\mathrm{Kg} / \mathrm{mm}^{2}\right)$ - Médias e desvios-padrão em relação ao acréscimo de fibra de vidro.

\begin{tabular}{cc}
\hline Reforço & Média ( \pm desvio padrão) \\
\hline Sem Fibra & $16.28( \pm 1.39)^{\mathrm{a}}$ \\
Com Fibra & $16.62( \pm 1.19)^{\mathrm{a}}$ \\
\hline${ }^{*}$ letras iguais indicam semelhança estatística
\end{tabular}

No gráfico 2, observa-se a interação dos fatores, a resina Vipi Crill com adição de fibra de vidro particulada apresentou-se com a maior média de dureza Vickers $(18,02)$, seguida pela Vipi Crill sem fibra de vidro com $(17,78)$, Vipi Wave com fibra $(17,25)$, Lucitone com fibra $(16,69)$, Vipi Wave sem fibra $(16,60)$, QC-20 com fibra (15,91), Vipi Flash com fibra (15,51). A resina Vipi Flash sem fibra foi a que apresentou a menor dureza $(15,35)$. 


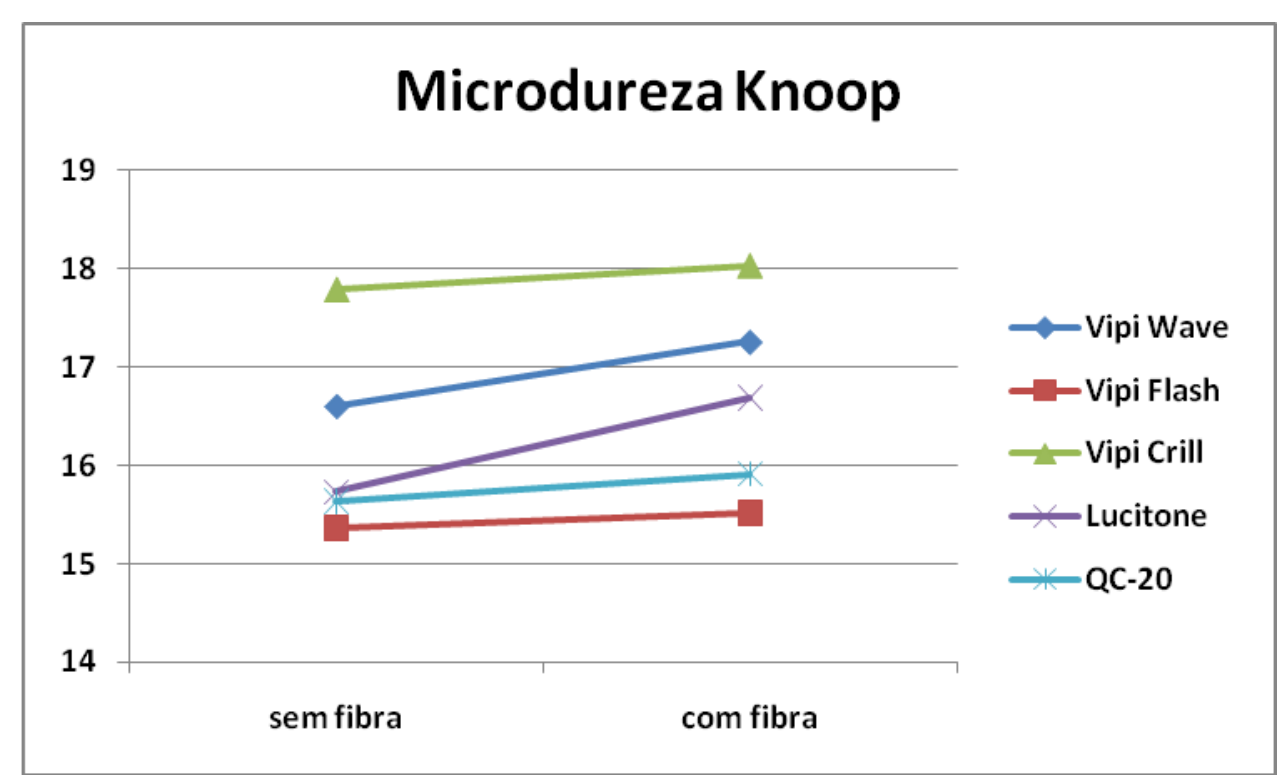

Grafico 2 - Microdureza Knoop após a incorporação das fibras de vidro particuladas.

\subsection{Módulo de elasticidade}

A análise estatística (ANOVA-TWO WAY) indicou semelhança $(p<0.05)$ entre o módulo de elasticidade das resinas, e também entre as resinas Vipi Wave, Vipi Flash e Vipi Crill. Contudo, os valores observados para as resinas Lucitone e QC-20 foram significativamente maiores $(p<0.05)$ em relação as demais resinas (Tabela 5).

Tabela 5 - Módulo de Elasticidade (MPa) - médias e desvios-padrão em relação ao fator marca comercial da resina

\begin{tabular}{cc}
\hline Resinas & Média ( \pm desvio padrão) \\
\hline Vipi Wave & $2868.35( \pm 454.46)^{\mathrm{a}}$ \\
Vipi Flash & $3163.13( \pm 406.15)^{\mathrm{a}}$ \\
Vipi Crill & $3208.64( \pm 561.85)^{\mathrm{a}}$ \\
Lucitone & $2480.70( \pm 603.85)^{\mathrm{b}}$ \\
QC-20 & $2386.09( \pm 509.47)^{\mathrm{b}}$ \\
\hline * letras iguais indicam semelhança estatística
\end{tabular}


A adição de fibras de vidro particuladas aumentou estatisticamente $(p<0.05)$ o modulo de elasticidade das resinas avaliadas (Tabela 6).

Tabela 6 - Módulo de Elasticidade (MPa) - Médias e desvios-padrão em relação ao acréscimo de fibra de vidro.

\begin{tabular}{cc}
\hline Reforço & Média ( \pm desvio padrão) \\
Sem Fibra & $2405.69( \pm 493.82)^{\mathrm{a}}$ \\
Com Fibra & $3237.07( \pm 386.77)^{\mathrm{b}}$ \\
\hline $\begin{array}{l}{ }^{*} \text { médias seguidas de mesma letra diferem entre si }(p<0,01) \\
\text { ou }(\mathrm{p}<0,05)\end{array}$
\end{tabular}

No gráfico 3, evidencia-se um aumento no módulo de elasticidade quando incorporadas fibras de vidro nas resinas. A resina Vipi Crill exibiu o maior valor, enquanto a Lucitone apresentou o maior ganho após a incorporação de fibras de vidro, seguida pelas resinas QC-20, Vipi Crill e Vipi Wave. O módulo de elasticidade da resina Vipi Flash foi o que menos se alterou após adição de fibras de vidro.

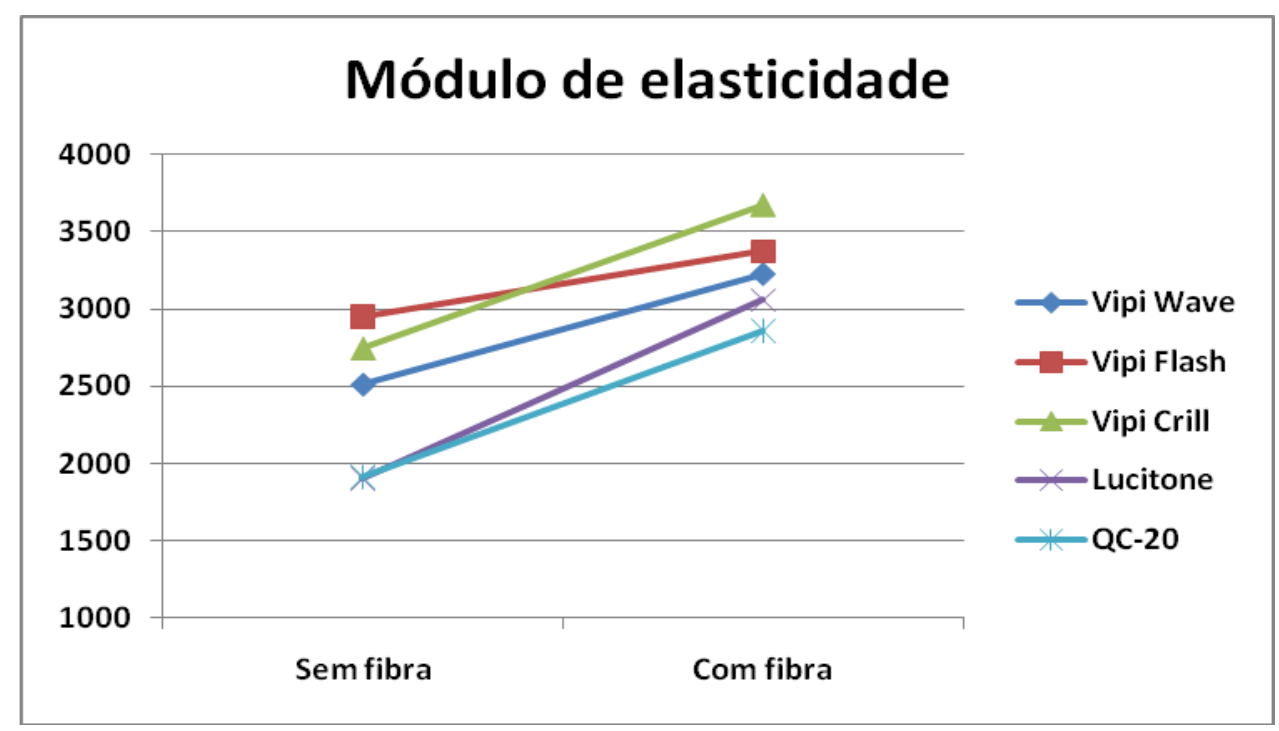

Grafico 3 - Módulo de Elasticidade após a incorporação das fibras de vidro particuladas. 
A análise estatística (ANOVA-TWO WAY) indicou a ocorrência de interação significante $(P<0,05)$ entre as resinas utilizadas e a adição de fibras de vidro. $A$ resina acrílica termopolimerizável Vipi Crill com fibra de vidro apresentou o maior valor de módulo de elasticidade $(3671,67 \pm 329,91)$, seguido pela resina Vipi Flash com fibra $(3373,49 \pm 403,76)$, Vipi Wave com fibra $(3225,01 \pm 248,66)$. As resinas Lucitone 550 com fibra $(3056,87 \pm 126,11)$, QC-20 com fibra $(2858,32 \pm$ $185,26)$, Vipi Flash sem fibra $(2952,76 \pm 292,12)$, Vipi Wave sem fibra $(2511,69 \pm$ 304,09) e Vipi Crill $(2745,61 \pm 288,86)$ exibiram módulos de elasticidade semelhantes (Tabela 7).

Tabela 7 - Módulo de Elasticidade (MPa) - médias e desvios-padrão

\begin{tabular}{cc}
\hline Resinas & Média $( \pm$ desvio padrão) \\
\hline Vipi Wave & $2511.69( \pm 304.09)^{\mathrm{a}}$ \\
Vipi Flash & $2952.76( \pm 292.12)^{\mathrm{b}}$ \\
Vipi Crill & $2745.61( \pm 288.86)^{\mathrm{a}}$ \\
Lucitone & $1904.53( \pm 149.05)^{\mathrm{c}}$ \\
QC-20 & $1913.86( \pm 147.80)^{\mathrm{c}}$ \\
Vipi Wave com fibra & $3225.01( \pm 248.66)^{\mathrm{d}}$ \\
Vipi Flash com fibra & $3373.49( \pm 403.76)^{\mathrm{e}}$ \\
Vipi Crill com fibra & $3671.67( \pm 329.91)^{\mathrm{f}}$ \\
Lucitone com fibra & $3056.87( \pm 126.11)^{\mathrm{b}}$ \\
QC-20 com fibra & $2858.32( \pm 185.26)^{\mathrm{b}}$ \\
\hline${ }^{*}$ médias seguidas de mesma letra diferem entre si $(\mathrm{p}<0,05)$
\end{tabular}




\subsection{Resistência flexural}

A análise estatística (ANOVA-TWO WAY) revelou diferença significante $(p<0.05)$ na resistência flexural em relação ao fator marca comercial de resinas acrílicas (Tabela 8).

Tabela 8 - Resultado do teste de Anova entre resinas: valores médios (MPa) e desvios-padrões.

\begin{tabular}{cc}
\hline Resinas & Média ( \pm desvio padrão) \\
\hline Vipi Wave & $86.25( \pm 8.89)^{\mathrm{a}}$ \\
Vipi Flash & $82.80( \pm 4.95)^{\mathrm{a}, \mathrm{b}}$ \\
Vipi Crill & $78.77( \pm 16.86)^{\mathrm{b}, \mathrm{c}}$ \\
Lucitone & $81.00( \pm 9.72)^{\mathrm{a}, \mathrm{c}, \mathrm{d}}$ \\
QC-20 & $78.74( \pm 11.25)^{\mathrm{b}, \mathrm{d}}$ \\
\hline
\end{tabular}

A adição de fibras de vidro particuladas aumentou significantemente $(p<0.05)$ a resistência flexural das resinas avaliadas (Tabela 9).

Tabela 9 - Valores médios (MPa) e desvios padrões dos corpos-de-prova com e sem fibras de vidro.

\begin{tabular}{cc}
\hline Reforço & Média ( \pm desvio padrão) \\
\hline Sem Fibra & $75.97( \pm 10.10)^{\mathrm{a}}$ \\
Com Fibra & $87.06( \pm 9.42)^{\mathrm{b}}$ \\
\hline${ }^{*}$ letras iguais indicam semelhança estatística
\end{tabular}

A análise estatística (ANOVA-TWO WAY) indicou a ocorrência de interação significante entre as resinas utilizadas e a adição de fibras de vidro (Tabela 10). 
Tabela 10 - Interação dos fatores. Valores médios (MPa) e desvios padrões dos corpos-de-prova com e sem fibras de vidro.

\begin{tabular}{cc}
\hline Resinas & Média ( \pm desvio padrão) \\
\hline Vipi Wave & $83.52( \pm 8.79) \mathrm{a}$ \\
Vipi Flash & $81.62( \pm 4.82) \mathrm{a}$ \\
Vipi Crill & $64.17( \pm 5.46) \mathrm{b}$ \\
Lucitone & $74.71( \pm 9.43) \mathrm{a}$ \\
QC-20 & $75.80( \pm 8.82) \mathrm{a}$ \\
Vipi Wave com fibra & $88.98( \pm 8.47) \mathrm{c}$ \\
Vipi Flash com fibra & $83.98( \pm 4.98) \mathrm{a}$ \\
Vipi Crill com fibra & $93.37( \pm 9.97) \mathrm{d}$ \\
Lucitone com fibra & $87.29( \pm 4.73) \mathrm{c}$ \\
QC-20 com fibra & $81.67( \pm 12.97) \mathrm{a}$ \\
\hline * letras iguais indicam semelhança estatística
\end{tabular}

No gráfico 4, nota-se um aumento nos valores de resistência flexural quando incorporadas fibras de vidro nas resinas acrílicas, sendo que a resina Vipi Cril apresentou a maior variação nos valores de resistência flexural, de 64,17 MPa para 93,37 $\mathrm{MPa}$.

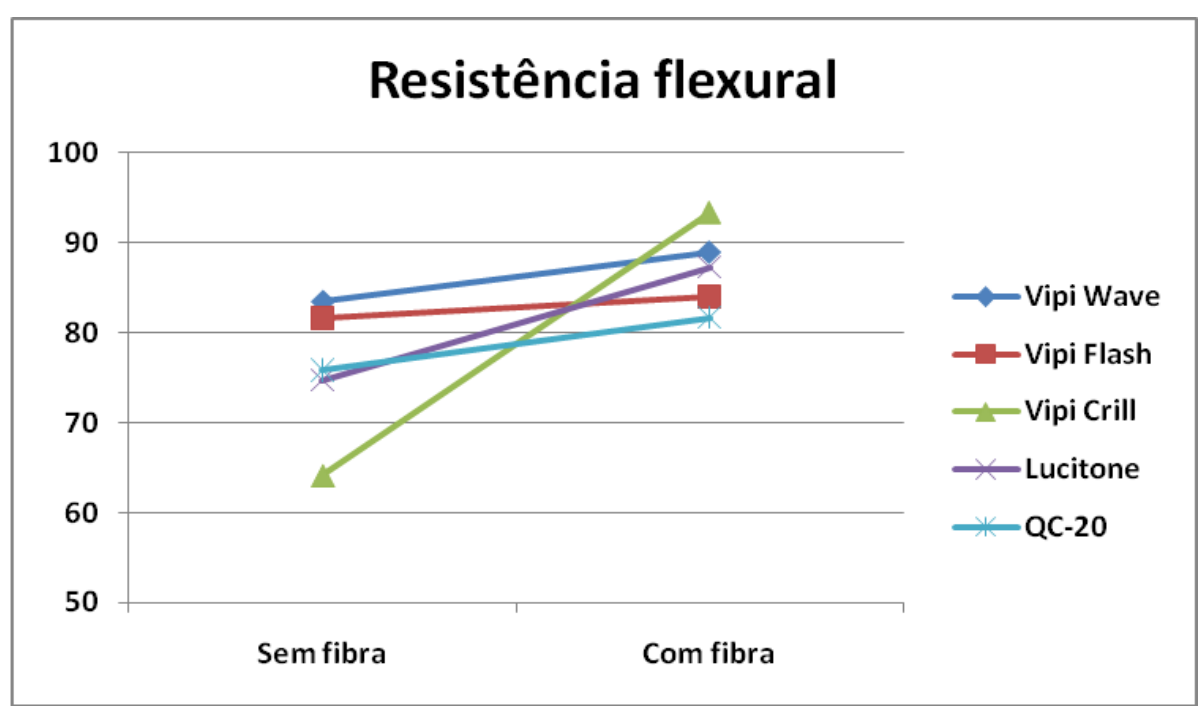

Grafico 4 - Resistência Flexural após a incorporação das fibras de vidro particuladas. 
5 Discussão 



\section{Discussão}

Resinas acrílicas são utilizadas até os dias atuais na odontologia por apresentarem muitas vantagens como excelente aparência, facilidade de manipulação, gasto mínimo, precisão e facilidade de ajuste no reparo (LEE, LAI, HSU, 2002). Porém este material ainda apresenta certas limitações, como as encontradas nas resinas autopolimerizáveis que possuem uma incompleta polimerização deixando restos de monômeros não reagidos, que atuam como plastificante, alterando desta forma as propriedades deste material.

Para solucionar tais inconvenientes alguns tipos de polimerização foram desenvolvidos dentre eles a polimerização por energia de microondas. Uma das vantagens deste método de polimerização é o menor tempo de processamento quando comparados com os métodos convencionais tais como os termoativados por banho de água (SOUZA JUNIOR, et al., 2006). Porém as resinas acrílicas utilizadas para a confecção de placas oclusais ainda podem se desgastar ou fraturar no caso de pacientes com algum hábito parafuncional, como o bruximo.

$\mathrm{Na}$ tentativa de melhorar algumas propriedades das resinas acrílicas alguns tipos de reforços têm sido propostos dentre eles o fio metálico, fibra de vidro, fibra de Kevlar, fibra de carbono, fibra de polietileno e materiais borrachóides (LEE, LAI, HSU, 2002).

Fibras de vidro têm boa biocompatibilidade, possuem uma capacidade adequada para a ligação à estrutura dentária e a outras resinas, são praticamente invisíveis quando incorporadas em resinas acrílicas e são facilmente manipulados na clínica ou laboratório (FRANKLIN, WOOD, BUBB, 2005). Tais fibras se tornaram muito populares nos últimos anos (ZORTUK, et al., 2008), sendo 
utilizadas em prótese parcial fixa (LEE, LAI, HSU, 2002), porém sua utilização em placas oclusais não é comum.

Vallittu et al., em 1999, relataram que as fibras instaladas longitudinalmente na resina mudaram de lugar quando uma pressão foi aplicada no molde, após a colocação em uma prensa hidráulica e que o seu paralelismo foi prejudicado, pois a forma de tecido é semelhante a um plano, seu contato com o acrílico foi problemático e houve problemas na ligação ao acrílico. Em 2008, Vojdani, Rezaei, Zareeian, fizeram um estudo com fibras de vidro picadas, verificaram que se uma elevada concentração de fibras fosse utilizada, poderia ocorrer uma diminuição na resistência, pois a adesão ideal entre a matriz polimérica e as fibras é essencial, o que é dificilmente encontrado em elevadas concentrações, principalmente quando não é feito nenhuma espécie de tratamento sobre as fibras com um agente de união como o silano. A proposta deste estudo foi utilizar uma proporção de $10 \%$ em peso de fibras de vidro particuladas (FREGONESI, 1985), tendo encontrado os melhores resultados em termos de reforço ao utilizar esta proporção. Uma vez que há características negativas observadas nas outras formas das fibras de vidro, o que não foi visto até o presente momento com as fibras de vidro particuladas e pré silanizadas (ZORTUK, et al., 2008), desta forma fibras deste tipo foram empregadas neste estudo.

Neste experimento, a simples mistura de fibras de vidro particuladas ao pó (polímero) da resina pode ser feito facilmente. As partículas de fibras de vidro são convenientemente homogeneizadas à matriz polimérica (LEE, LAI, HSU, 2002), uma vez que são pré silanizadas, o que aumenta a adesão (UZUN, HERSEK, TINÇER, 1999). A facilidade e simplicidade de sua inclusão tornariam esta técnica mais aceitável para sua utilização (LEE, LAI, HSU, 2002), com um consumo de 
tempo menor, pois não há necessidade de orientar as fibras para ficarem em zonas de tensão, uma vez que fibras com tamanho menores são distribuídas por todo o corpo da resina acrílica (CZIGÁNY, NÉMETH, ELINGER, 2001; ZORTUK, et al., 2008), promovendo um importante papel na transmissão de carga da matriz para a fibra (ANUSAVICE, 2003).

Embora o efeito de fibras de vidro na resistência das resinas é bem conhecido, o mesmo não pode ser dito sobre o seu efeito sobre a rugosidade de superfície. Placas oclusais utilizadas por bruxistas podem ficar com irregularidades na superfície e mais ásperas. A presença de superfícies rugosas leva à presença de micro espaços sobre as resinas acrílicas que são facilmente colonizadas e aderidas por microorganismos (BOLLEN, LAMBRECHTS, QUIRYNEN, 1997; BERGER, et al., 2006).

Tais microorganismos são responsáveis pela formação da placa bacteriana que é considerada uma massa densa não calcificada firmemente aderida à superfície dura. Este conceito é de importância clínica porque as superfícies lisas impedem a formação de biofilme (BERGER, et al., 2006; ZORTUK, et al., 2008).

A principal forma de medir uma superfície irregular é por meio da rugosidade superficial que é uma média da rugosidade representada pelo parâmetro $(\mathrm{Ra})$. A rugosidade é dada pela variação aritmética média de reentrâncias e saliências feita por uma ponta analisadora, sobre superfícies rígidas (RADFORD; CHALLACOMBE; WALTER, 1999).

A rugosidade de superfície dos materiais dentários influência na formação da placa bacteriana, descoloração, abrasão e aparência estética (ZORTUK, et al., 2008). 
Segundo Bollen; Lambrechts; Quirynen, em 1997, o ideal seria que a rugosidade de resinas acrílicas estivesse por volta de 0,2 $\mu \mathrm{m}$ (SOUZA JUNIOR, et al., 2006; ZORTUK, et al., 2008), só assim a adesão de microorganismos seria dificultada. Porém, um valor tão baixo de rugosidade torna-se difícil de ser atingido, por meio de técnicas convencionais de polimento.

Um dos grandes inconvenientes quando se utiliza a rugosidade de resinas acrílicas é que na literatura há controvérsia, uma vez que a rugosidade de superfície depende da forma pela qual foi feito o polimento da superfície (BOLLEN; LAMBRECHTS; QUIRYNEN, 1997).

O processo de polimento em um ambiente clínico ou no laboratório não é perfeitamente executado em superfícies lisas como é o caso dos estudos, in vitro (ZORTUK, et al., 2008). A razão para isso é que próteses e placas oclusais têm superfícies côncavas e convexas, que dificultam o polimento mecânico. A padronização de acordo com um protocolo in vitro e sua incapacidade de refletir idealmente condições clínicas são as suas principais limitações de estudos laboratoriais (ZORTUK, et al., 2008).

Levando-se em consideração a marca comercial das resinas, os maiores valores de rugosidade de superfície foram encontrados na Vipi Crill que é uma resina termopolimerizável por banho de água, apresentando uma média de 0,13 Ra. O menor valor de rugosidade de superfície foi o da resina Lucitone com uma média de 0,09 Ra que também é uma resina termopolimerizável por banho de água. Já as resinas termopolimerizável por calor de microondas, Vipi Wave com média de 0,11 Ra, a resina Vipi Flash autopolimerizável, com média de 0,10 Ra e a resina QC-20, termopolimerizável por calor de banho de água, com média 0,11 $\mathrm{Ra}$, foram estatisticamente semelhantes, apresentando o mesmo comportamento. 
As resinas Lucitone e QC-20 mesmo após a incorporação de fibras de vidro mantiveram os valores de rugosidade superficial encontrado quando não eram reforçadas com tais fibras. Uma possível explicação é que estas resinas são do mesmo fabricante, diferem na composição dos polímeros apenas pela resina QC20 apresentar corantes naturais e a Lucitone apresentar corantes minerais. Outra pequena diferença se encontra no monômero, pois a resina QC-20 apresenta alguns componentes como o N,N-dimetil-p-toluidina, que a resina Lucitone não possui.

Neste estudo não foram realizados métodos auxiliares de impregnação das fibras de vidro uma vez que estas já vêm de fábrica pré-impregnadas por um agente silano mais uma resina epóxica. Caso não exista uma correta impregnação, as fibras de reforço podem ser expostas durante o acabamento da placa (SOUZA JUNIOR, et al., 2006). Isso pode levar a uma situação em que as fibras entram em contato com o meio ambiente oral e podem proporcionar retenção de biofilme na interface dos componentes (KARAAGACLIOGLU et al., 2008). Porém para que ocorra uma combinação bem sucedida do reforço com fibra de vidro às resinas acrílicas utilizadas para a confecção de placas oclusais, outra impregnação por silano ou outro material que promova união seja necessária, pois somente com uma união química completa das fibras de vidro às resinas acrílicas possam reduzir drasticamente a aspereza (LEE, LAI, HSU, 2002).

De acordo com os resultados das resinas avaliadas, as resinas Vipi Crill, Vipi Flash e Vipi Wave apresentaram um aumento na rugosidade superficial. Segundo Zortuk et al., em 2008, uma possível explicação para tal aumento pode 
ser que a concentração das fibras de vidro pode afetar a distribuição, o arranjo ou a natureza química das resinas acrílicas, deixando desta forma a superfície da resina mais rugosa.

Em favor deste estudo Lee, Lai, Hsu, 2002 encontraram que a adição de fibras de vidro incluídas em resinas acrílicas não alterou os valores de rugosidade superficial, como pode ser verificado nas resinas Lucitone e QC-20.

Segundo Berger, et al., em 2006, as resinas termopolimerizáveis apresentaram menor rugosidade do que as resinas autopolimerizáveis. Os autores esclarecem que a autopolimerização da resina acrílica tende a ter uma superfície mais áspera do que as outras resinas acrílicas termopolimerizáveis, pois o polímero da resina autopolimerizável pode ter um maior tamanho de partícula de acrílico que os outros tipos de resinas termoativas. O que não foi verificado neste estudo em que a resina autopolimerizável apresentou um comportamento semelhante ao das demais resinas acrílicas termopolimerizáveis utilizadas.

A dureza e o tipo de desordem são fatores relevantes na seleção do material para a confecção da placa oclusal. Portanto, buscou-se com esse estudo analisar a microdureza Knoop de diferentes tipos de resinas, com e sem a adição de fibra de vidro particuladas.

O teste de microdureza pode ser usado para prever o desgaste que os materiais odontológicos podem sofrer quando submetidos a tensões (CRAIG, POWERS, 2002). A microdureza Knoop é um método válido para avaliar a rigidez dos materiais (LOW, 1998). Adequada rigidez fornece conforto e estabilidade (O’BRIEN, 1996). O teste de microdureza Knoop consiste em verificar a 
capacidade que a superfície de um material tem de resistir à penetração de um ponto sob uma determinada carga (ANUSAVICE, 2003). Ele é uma maneira simples e eficaz de avaliar o grau de conversão do monômero em polímero (O’BRIEN, 1996) durante a reação de polimerização (ANUSAVICE, 2003).

Muitos fatores afetam as propriedades das resinas acrílicas, incluindo a composição química da cadeia, o grau de polimerização e o número de ramificações e ligações cruzadas entre a cadeia polimérica (ANUSAVICE, 2003). De acordo com os resultados deste estudo, a resina acrílica termopolimerizável Vipi Crill apresentou melhores resultados de dureza quando comparada as outras resinas termopolimerizáveis, seja por polimerização por calor de microondas ou por banho em água. Isso se deve pelo fato que as propriedades físicas das resinas são influenciadas por mudanças de temperatura e ambiente e pela composição estrutural e peso molecular deste composto (ANUSAVICE, 2003).

Os menores valores de microdureza Knoop foram da resina acrílica autopolimerizável, Vipi Flash, isso pode ter sido causado pelo fato do monômero não se converter completamente em polímero durante a reação de polimerização (DOGAN et al., 1995; KEDJARUNE, CHAROENWORALUK, KOONTONGKAEW, 1999) uma vez que o monômero residual é bem conhecido como plastificante e diminui a resistência dos materiais (BRAUN et al., 2003; BOTEGA et al., 2004). De acordo com Anusavice 2003, o grau de polimerização alcançado pela resina autopolimerizável não se completa como nas termoativas. Assim, a maior dureza encontrada nas resinas termoativas sugere uma menor quantidade de monômero residual e uma melhor conversão do monômero em polímero durante a reação de polimerização (LEE, LAI, HSU, 2002; VALLITTY, RUYTER, BUYKUILMAZ, 1998). 
Contrário aos resultados do presente estudo, Meiers et al., em 1998, encontrou que os compósitos reforçados com fibras de vidro pré impregnadas exibiram um aumento acima de 3 vezes na dureza em relação aos materiais sem adição de fibras.

De acordo com os estudos de Vallittu, Lassila, Lappalainem, 1994; Uzun, Hersek, Tinçer, em 1999 e Chen, Liang, Yen, 2001, fibras de vidro quando foram adicionadas as resinas acrílicas não apresentaram uma melhora nas propriedades dos materiais testados. Uma possível explicação é a ausência de união completa das fibras à matriz resinosa, uma vez que não foram feitos nenhuma espécie de tratamento nas fibras ou na resina para aumentar a união, já que, segundo o fabricante, as fibras de vidro vêm pré-impregnadas de fábrica.

As resinas acrílicas devem ainda ser capazes de resistir às forças mastigatórias, força de impacto, e desgaste excessivo que podem ocorrer na cavidade oral, principalmente em pacientes que apresentam um quadro típico de apertamento dental e/ou bruxismo. Nestas situações de sobrecarga oclusal as resinas acrílicas podem falhar por não apresentarem um adequado módulo de elasticidade o que poderia acarretar na flexão do material levando a uma fratura (O'BRIEN, 1996).

Quando as fibras de vidro particuladas foram adicionadas às resinas acrílicas houve um aumento significante nos valores do módulo de elasticidade. A resina Vipi Cril apresentou um maior módulo de elasticidade, assim quando fibras de vidro foram adicionadas, seu valor também se elevou proporcionalmente, porém a resina Lucitone 550 foi à resina que melhor se beneficiou da adição destas fibras à matriz polimérica, pois foi à resina que apresentou a maior melhora no módulo de elasticidade. 
A resina que apresentou a menor alteração quando foram adicionadas as fibras de vidro particuladas foi à resina Vipi Flash, que era a única resina autopolimerizável. Este resultado pode ter sido causado pelo fato do monômero não se converter completamente em polímero durante a reação de polimerização (DOGAN et al., 1995; KEDJARUNE, CHAROENWORALUK, KOONTONGKAEW, 1999) deixando resíduos de monômero residual que diminuem a resistência dos materiais (BRAUN et al., 2003). Como o grau de polimerização alcançado pela resina autopolimerizável não se completa como nas termoativadas (ANUSAVICE, 2003), o maior módulo de elasticidade encontrado nas resinas termopolimerizáveis por banho de água sugere uma menor quantidade de monômero residual e uma melhor conversão do monômero em polímero durante a reação de polimerização (VALLITTU, RUYTER, BUYKUILMAZ, 1998; LEE, LAI, HSU, 2002).

Bayraktara, Duranb, Guvener, em 2003, sugerem que a resina autopolimerizável deve ser mantida sobre pressão por no mínimo 2,5 horas. Segundo os autores, desta forma pode-se reduzir o monômero residual, pois a polimerização da resina seria mais completa, com menor quantidade de oxigênio, uma vez que este elemento inibe a polimerização da resina acrílica.

A resistência de resinas acrílicas empregadas para confecção de placas oclusais, é determinada pela resistência do material à propagação de fendas e fratura, as quais podem ocorrer devido às resistências flexural, ao impacto e à fadiga inadequada (BURNS; BECK; NELSON, 2003). Para avaliar as fibras de vidro particuladas deste estudo foi proposta a análise também pelo teste de resistência flexural, uma vez que representa a resistência máxima ao dobramento 
de um material antes que ocorra a fratura (GAROUSHI, VALLITTU, LASSILA, 2008). Além disto, o teste determina a quantidade de distorção esperada (CRAIG; POWER, 2004).

Os resultados deste estudo evidenciaram diferenças significantes na resistência flexural entre marcas comerciais de resina acrílica; Vipi Wave apresentou resistência flexural superior às resinas Vipi Flash, Lucitone, Vipi Crill e QC-20. Essa diferença entre as marcas comerciais pode estar relacionada à composição química (VOJDANI, REZAEI, ZAREEIAN, 2008). Os componentes metilmetacrilato, EDMA (crosslink) e um inibidor são encontrados no líquido das resinas Vipi Cril e Vipi Wave. Com relação ao polímero tais resinas praticamente não diferem, apresentando copolímero metilmetacrilato, peróxido de benzoíla e pigmentos. A resina Vipi Flash possui em seu líquido o metilmetacrilato, DMT e um inibidor, já o polímero é semelhante ao das Vipi Crill e Vipi Wave. Com relação à resina Lucitone 550, esta apresenta em seu líquido os componentes metacrilato de metila, etileno glicol dimetacrilato, hidronquinona que difere da resina $\mathrm{QC}-20$ que além destes componentes apresenta o terpinoleno, N,N-dimetil-p-toluidina.

Outra diferença significante foi quanto à incorporação de fibras de vidro, que tornou todas as resinas acrílicas mais resistentes com uma média de 75,97 $\mathrm{MPa}$ (controle) e uma média de 87,06 MPa (experimental), com exceção da resina Vipi Flash que apresentou uma melhora, porém não significante.

Com relação à interação dos fatores pode-se verificar pelo gráfico 4, que a resina Vipi Cril foi a resina que apresentou a maior melhora quando fibras de vidro particuladas foram acrescidas, partindo de um valor inicial de $64,17 \mathrm{MPa}$ (controle) sem a adição de fibras de vidro, para um valor médio de 93,37 MPa, (experimental) com a adição de fibras de vidro. A resina Vipi Flash foi a resina que 
apresentou a menor variação entre os valores do grupo controle $81,62 \mathrm{MPa}$ e experimental 83,98 MPa. As demais resinas apresentaram valores intermediários.

De acordo com este estudo Vallittu (1999), Lassila et al., 2005; Vojdani, Rezaei, Zareeian, 2008, relataram que a resistência flexural aumentou, já os estudos de Balkenhol et al. (2008), Dogan et al. (2008), demonstraram diminuição.

Devido à natureza particular dos ingredientes encontrados nas resinas acrílicas, segredos de fábrica, algumas perguntas podem ficar sem resposta.

Uma vez que a Disfunção da Articulação temporomandibular (DTM) é um distúrbio funcional muito destrutivo para os dentes, provocando erosão, abrasão, mobilidade dental e oclusal e danos aos tecidos de suporte, o portador dessa patologia necessitaria de placa confeccionada em resina com maior dureza superficial e resistência para suportar as tensões exercidas. A utilização de fibras de vidro particuladas não mostrou melhora significante na microdureza Knoop dos materiais testados, porem aumentou a resistência flexural e o módulo de elasticidade consideravelmente, e apresentou um leve aumento na rugosidade superficial, podendo ser utilizadas rotineiramente na clinica odontológica, embora mais pesquisas sejam necessárias para determinar se as fibras de vidro alteram outras propriedades mecânicas assim como se são cancerígenas na boca, atraem mais placa bacteriana, ou doenças gengivais ou até mesmo a utilização de outros agentes de união complementares para promover a completa união entre estes materiais, e desta forma aumentar a dureza das resinas utilizadas. 

6 Conclusões 



\section{CONCLUSÕES}

1. As resinas com fibras de vidro apresentaram maiores valores de rugosidade superficial com relação às resinas sem reforço com fibras de vidro. Houve um aumento nos valores de rugosidade superficial quando foram incorporadas fibras de vidro nas resinas Vipi Flash, Vipi Crill, Vipi Wave, porém as resinas QC-20 e Lucitone apresentaram os mesmos valores na rugosidade superficial quando fibras de vidro particuladas foram utilizadas.

2. As resinas acrílicas termopolimerizável por banho de água e termopolimerizável por calor de microondas apresentaram maiores valores de microdureza Knoop quando comparados com a resina acrílica autopolimerizável. A adição de fibra de vidro aos grupos experimentais não alterou os valores de microdureza Knoop.

3. As resinas Lucitone e QC-20 apresentaram os menores valores de módulo de elasticidade em relação à Vipi Cril, Vipi Flash e Vipi Wave, que apresentaram os maiores, respectivamente. A adição de fibra de vidro particuladas aumentou consideravelmente o módulo de elasticidade de todas as resinas nos grupos em estudo.

4. Fibras de vidro particuladas aumentaram significantemente os valores de resistência flexural. $\quad$ A resina Vipi Cril apresentou a maior alteração nos valores de resistência flexural quando fibras de vidro particuladas foram utilizadas. A resina Vipi Flash apresentou a menor alteração nos valores de resistência flexural quando fibras de vidro particuladas foram utilizadas 

7 Referências 



\section{REFERÊNCIAS}

1. AMORIM CF, GIANNASI LC, FERREIRA LMA, MAGINI M, OLIVEIRA CS D, OLIVEIRA LVF, HIRATA T. Behavior analysis of electromyographic activity of the masseter muscle in sleep bruxers. Journal of Bodywork \& Movement Therapies. 2009; xx, 1-5.

2. ANUSAVICE, KJ. Philip's science of dental materials. 11th ed. 11 St. Louis: Elsevier Science; 2003. p. 140-160.

3. BALKENHOL, M.; MAUTNER, M.C.; FERGER, P.; WÖSTMANN, B. Mechanical properties of provisional crown and bridge materials: Chemicalcuring versus dual-curing systems. J Dent, v. 36, n. 1, p. 15-20, jan. 2008.

4. BAYRAKTARA G, DURANB O, GUVENER B. Effect of glass fibre reinforcement on residual methyl methacrylate content of denture base polymers. J Dent, 2003; 31(4):297-302.

5. BERGER JC, DRISCOLL CF, ROMBERG E, LUO Q, THOMPSON G. Surface roughness of denture base acrylic resins after processing and after polishing. J Prosthodont. 2006 May-Jun;15(3):180-6.

6. BOLLEN CM, LAMBRECHTS P, QUIRYNEN M. Comparison of surface roughness of oral hard materials to the threshold surface roughness for bacterial plaque retention: a review of the literature. Dent Mater. 1997 Jul;13(4):258-69.

7. BOTEGA DM, DE SOUZA MACHADO T, DE MELLO JA, GARCIA RC, DEL BEL CURY AA. Polymerization time for a microwave-cured acrylic resin with multiple flasks. Braz Oral Res. 2004 Jan-Mar;18(1):23-8. Epub 2004 Jul 20.

8. BRAUN KO, MELLO JA, RACHED RN, DEL BEL CURY AA. Surface Texture And Some Properties Of Acrylic Resins Submitted To Chemical Polishing. $\mathbf{J}$ Oral Rehabil, 2003;30:91-8. 
9. BURNS DR, BECK DA, NELSON SK. A review of selected dental literature on contemporary provisional fixed prosthodontic treatment: report of the Committee on Research in Fixed Prosthodontics of the Academy of Fixed Prosthodontics. J Prosthet Dent. 2003 Nov;90(5):474-97.

10. CHEN SY, LIANG WM, YEN PS. Reinforcement of acrylic denture base resin by incorporation of various fiber. J Biomed Mater Res 2001;58(2): 203-8.

11. CRAIG RG, POWERS JM. Restorative dental materials. St Louis: Mosby; 2002.

12. CZIGÁNY, T., NÉMETH, A., ELINGER, I.: Investigation of knitted fabric reinforced GF/PP composites by acoustic emission and infrared thermography, Periodica Polytechnica Mechanical Engineering, (2000).

13. DAO TT, LAVIGNE GJ. Oral splints: the crutches for temporomandibular disorders and bruxism? Crit Rev Oral Biol Med. 1998;9(3):345-61.

14. DARBAR UR, HUGGETT R, HARRISON A. Denture fracture - A survey. Br Dent J 1994;176:342-345.

15. DOGAN A, BEK B, CEVIK NN, USANMAZ A. The Effect Of Preparation Conditions Of Acrylic Denture Base Materials On The Level Of Residual Monomer, Mechanical Properties And Water Absorption. J Dent, 1995; 23:313-8.

16. DOĞAN, O.M.; BOLAYIR, G.; KESKIN, S.; DOĞAN, A.; BEK, B. The evaluation of some flexural properties of a denture base resin reinforced with various aesthetic fibers. J Mater Sci Mater Med, v. 19, n. 6, p. 2343-2349, jun. 2008.

17. DUNCAN JP, FREILICH MA, LATVIS CJ. Fiber-reinforced composite framework for implant-supported overdentures. J Prosthet Dent. 2000 Aug;84(2):200-4.

18. FERRARIO VF, SFORZA C, TARTAGLIA GM, DELLAVIA C. Immediate effect of a stabilization splint on masticatory muscle activity in temporomandibular disorder patients. J Oral Rehabil. 2002 Sep;29(9):810-5. 
19. FERRARIO VF, SFORZA C. Biomechanical model of the human mandible in unilateral clench: distribution of temporomandibular joint reaction forces between working and balancing sides. J Prosthet Dent. 1994 Aug;72(2):16976.

20. FRANKLIN, P.; WOOD, D.J.; BUBB, N.L. Reinforcement of poly (methyl methacrylate) denture base with glass flake. Dent Mater, v. 21, n. 4, p. 36570, apr. 2005.

21. FREGONESI, L.A. Medidas de resistência e deformação de resina acrílica reforçada com fibras de vidro picadas e moídas [Dissertação de Mestrado]. Ribeirão Preto: Faculdade de Odontologia de Ribeirão Preto da USP; 1985.

22. FREILICH MA, DUNCAN JP, MEIERS JC, GOLDBERG AJ. Preimpregnated, fiber-reinforced prostheses. Part I. Basic rationale and complete-coverage and intracoronal fixed partial denture designs. Quintessence Int. 1998 Nov;29(11):689-96.

23. GAROUSHI, S.; VALLITTU, P.K.; LASSILA, L.V.J. Short glass fiber-reinforced composite with a semi-interpenetrating polymer network matrix for temporary crowns and bridges. J Contemp Dent Pract, v. 9, n.1, p. 14-21, jan. 2008.

24. GIVENS, E.J.Jr.; NEIVA, G.; YAMAN, P.; DENNISON, J.B. Marginal adaptation and color stability of four provisional materials. Journal of Prosthodontics, v. 17, n. 2, p. 97-101, feb. 2008.

25. HAMZA, T.A.; ROSENSTIEL, S.F.; ELHOSARY, M.M.; IBRAHEEM, R.M. The effect of fiber reinforcement on the fracture toughness and flexural strength of provisional restorative resins. J Prosthet Dent, v. 91, n. 3, p. 258-264, mar. 2004.

26. KANIE T, FUJII K, ARIKAWA H, INOUE K. Adding silanes to MMA: the effects on the water absorption, adhesive strength and mechanical properties of acrylic denture base resins. Dent Mater J. 2000 Dec;19(4):329-37. 
27. KANIE, T.; FUJII, K.; ARIKAWA, H.; INOUE, K. Flexural properties and impact strength of denture base polymer reinforced with woven glass fibers. Dent Mater, v. 16, n. 2, p. 150-8, mar. 2000.

28. KARAAGACLIOGLU, L.; CAN, G.; YILMAZ, B.; AYHAN, N.; SEMIZ, O.; LEVENT, $H$. The adherence of Candida albicans to acrylic resin reinforced with different fibers. J Mater Sci Mater Med, v. 19, n. 2, p. 959-963, feb. 2008.

29. KEDJARUNE U, CHAROENWORALUK N, KOONTONGKAEW S. Release of methyl methacrylate from heat-cured and autopolymerized resins: cytotoxicity testing related to residual monomer. Aust Dent J. 1999 Mar;44(1):25-30.

30. KEYF, F.; UZUN, G.; MUTLU, M. The effects of HEMA-monomer and air atmosphere treatment of glass fibre on the transverse strength of a provisional fixed partial denture resin. J Oral Rehabil, v. 30, n. 11, p. 1142-1148, nov. 2003.

31. KIM, S.H.; WATTS, D.C. Polymerization shrinkage-strain kinetics of temporary crown and bridge materials. Dent Mater, v. 20, n. 1, p. 88-95, jan. 2004.

32. LANDULPHO AB, E SILVA WA, E SILVA FA, VITTI M. The effect of the occlusal splints on the treatment of temporomandibular disorders--a computerized electromyographic study of masseter and anterior temporalis muscles. Electromyogr Clin Neurophysiol. 2002 Apr-May;42(3):187-91.

33. LASSILA LV, TEZVERGIL A, LAHDENPERÄ M, ALANDER P, SHINYA A, SHINYA A, VALLITTU PK. Evaluation of some properties of two fiberreinforced composite materials. Acta Odontol Scand. 2005 Aug;63(4):196204.

34. LEE SY, LAI YL, HSU TS. Influence Of Polymerization Conditions On Monomer Elution And Microhardness Of Autopolymerized Polymethyl Methacrylate Resin. Eur J Oral Sci, 2002;110:179-83.

35. LOW IM. Effects of load and time on the hardness of a viscoelastic polymer. Materials Research Bulletin 1998;33:1753. 
36. MEIERS JC, DUNCAN JP, FREILICH MA, GOLDBERG AJ. Preimpregnated, fiber-reinforced prostheses. Part II. Direct applications: splints and fixed partial dentures. Quintessence Int. 1998 Dec;29(12):761-8.

37. O'BRIEN, W. Dental materials and their selection, 2th .ed., Quintessence Pubh.,1996.

38. PAIVA G, MAZZETTO MO. Atlas De Placas Interoclusais. Editora Santos, 2008.

39. POLYZOIS GL, ANDREOPOULOS AG, LAGOUVARDOS PE. Acrylic resin denture repair with adhesive resin and metal wires: effects on strength parameters. J Prosthet Dent. 1996 Apr;75(4):381-7.

40. RADFORD DR, CHALLACOMBE SJ, WALTER JD. Denture plaque and adherence of Candida albicans to denture-base materials in vivo and in vitro. Crit Rev Oral Biol Med. 1999;10(1):99-116.

41. RUEGGEBERG FA, CRAIG RG. Correlation of parameters used to estimate monomer conversion in a light-cured composite. J Dent Res. 1988 Jun;67(6):932-7.

42. SAMADZADEH, A.; KUGEL, G.; HURLEY, E.; ABOUSHALA, A. Fracture strengths of provisional restorations reinforced with plasma-treated woven polyethylene fiber. J Prosthet Dent, v. 78, n. 5, p. 447-50, nov. 1997.

43. SOUZA JÚNIOR JA, GARCIA RC, MOURA JS, DEL BEL CURY AA. Influence of a cobalt-chromium metal framework on surface roughness and Knoop hardness of visible light-polymerized acrylic resins. J Appl Oral Sci. 2006 Jun;14(3):208-12.

44. STIPHO HD, TALIC YF. Repair of denture base resins with visible lightpolymerized reline material: effect on tensile and shear bond strengths. $\mathbf{J}$ Prosthet Dent. 2001 Aug;86(2):143-8.

45. TACIR ,I.H.; KAMA, J.D.; ZORTUK, M.; ESKIMEZ, S. Flexural properties of glass fibre reinforced acrylic resin polymers. Aust Dent J, v. 51, n. 1, p. 52-56, mar. 2006. 
46. TACIR ,I.H.; KAMA, J.D.; ZORTUK, M.; ESKIMEZ, S. Flexural properties of glass fibre reinforced acrylic resin polymers. Aust Dent J, v. 51, n. 1, p. 52-56, mar. 2006.

47. UZUN, G.; HERSEK, N.; TINÇER T: Effect of five woven fiber reinforcements on the impact and transverse strength of a denture base resin. $\mathbf{J}$ Prosthet Dent, v. 81, n. 5, p. 616-620, may. 1999.

48. UZUN, G.; HERSEK, N.; TINÇER T: Effect of five woven fiber reinforcements on the impact and transverse strength of a denture base resin. $\mathbf{J}$ Prosthet Dent, v. 81, n. 5, p. 616-620, may. 1999.

49. VALLITTU PK, LASSILA VP, LAPPALAINEM R. Acrylic resin-fiber composite - part 1: the effect of fiber concentration on resistance fracture. $\mathbf{J}$ Prosthet Dent 1994: 71(6): 607-12.

50. VALLITTU PK, LASSILA VP. Reinforcement of acrylic resin denture base material with metal or fibre strengtheners. J Oral Rehabil. 1992 May;19(3):225-30.

51. VALLITTU PK, RUYTER IE, BUYKUILMAZ S. Effect of polymerization temperature and time on the residual monomer of denture base polymers. Eur J Oral Sci. 1998;106:588-93

52. VALLITTU PK. Comparison of the in vitro fatigue resistance of an acrylic resin removable partial denture reinforced with continuous glass fibers or metal wires. J Prosthodont 1996;5:115-21.

53. VALLITTU PK. Effect of some properties of metal strengtheners on the fracture resistance of acrylic denture base material construction. J Oral Rehab 1993;20:241-248.

54. VALLITTU PK; VOJTKOVA H; LASSILA VP. Impact strength of denture polymetil methacrylate reinforced with continuous glass fibers or metal wire. Acta Odontol Scan 1995; 53:392-6. 
55. VALLITTU, P.K. Flexural Properties Of Acrylic Resin Polymers Reinforced With Unidirectional And Woven Glass Fibers. J Prosthet Dent, 1999; 81:31826.

56. VALLITTU, P.K. Flexural Properties Of Acrylic Resin Polymers Reinforced With Unidirectional And Woven Glass Fibers. J Prosthet Dent, 1999; 81:31826.

57. VERRAN J, MARYAN CJ. Retention of Candida albicans on acrylic resin and silicone of different surface topography. J Prosthet Dent. 1997 May;77(5):535-9.

58. VISSER A, NAEIJE M, HANSSON TL. The temporal/masseter co-contraction: an electromyographic and clinical evaluation of short-term stabilization splint therapy in myogenous CMD patients. J Oral Rehabil. 1995 May;22(5):387-9.

59. VOJDANI M, REZAEI S, ZAREEIAN L. Effect of chemical surface treatments and repair material on transverse strength of repaired acrylic denture resin. Indian J Dent Res. 2008 Jan-Mar;19(1):2-5.

60. ZORTUK M, KILIC K, UZUN G, OZTURK A, KESIM B. The Effect of Different Fiber Concentrations on the Surface Roughness of Provisional Crown and Fixed Partial Denture Resin. Eur J Dent. 2008 Jul;2:185-190. 

Apêndices 



\section{APÊNDICE A}

\section{RUGOSIDADE DE SUPERFÍCIE}

Tabela 1 - Valores calculados de rugosidade de superfície.

\begin{tabular}{|c|c|c|}
\hline \multirow[b]{2}{*}{ Resinas } & \multicolumn{2}{|c|}{ Tratamentos } \\
\hline & Sem fibras & Com fibras \\
\hline \multirow{12}{*}{ VIPI WAVE } & 0,13 & 0,11 \\
\hline & 0,13 & 0,09 \\
\hline & 0,09 & 0,12 \\
\hline & 0,14 & 0,10 \\
\hline & 0,09 & 0,11 \\
\hline & 0,10 & 0,13 \\
\hline & 0,15 & 0,16 \\
\hline & 0,08 & 0,13 \\
\hline & 0,07 & 0,14 \\
\hline & 0,07 & 0,11 \\
\hline & 0,07 & 0,12 \\
\hline & 0,07 & 0,11 \\
\hline \multirow{15}{*}{ VIPI FLASH } & 0,10 & 0,12 \\
\hline & 0,03 & 0,02 \\
\hline & 0,08 & 0,11 \\
\hline & 0,09 & 0,08 \\
\hline & 0,08 & 0,13 \\
\hline & 0,15 & 0,13 \\
\hline & 0,15 & 0,13 \\
\hline & 0,16 & 0,15 \\
\hline & 0,14 & 0,19 \\
\hline & 0,12 & 0,21 \\
\hline & 0,18 & 0,18 \\
\hline & 0,08 & 0,13 \\
\hline & 0,09 & 0,17 \\
\hline & 0,16 & 0,14 \\
\hline & 0,12 & 0,15 \\
\hline \multirow{9}{*}{ VIPI CRIL } & 0,04 & 0,04 \\
\hline & 0,10 & 0,16 \\
\hline & 0,09 & 0,11 \\
\hline & 0,12 & 0,16 \\
\hline & 0,09 & 0,13 \\
\hline & 0,11 & 0,10 \\
\hline & 0,08 & 0,12 \\
\hline & 0,06 & 0,11 \\
\hline & 0,15 & 0,11 \\
\hline
\end{tabular}




\begin{tabular}{ccc}
\hline & 0,11 & 0,12 \\
0,08 & 0,15 \\
0,08 & 0,12 \\
0,11 & 0,13 \\
LUCITONE & 0,10 & 0,13 \\
0,02 & 0,02 \\
0,08 & 0,09 \\
0,11 & 0,06 \\
0,12 & 0,13 \\
0,10 & 0,11 \\
0,06 & 0,11 \\
\hline 0,13 & 0,08 \\
0,09 & 0,20 \\
0,09 & 0,12 \\
0,09 & 0,07 \\
0 & 0,13 & 0,05 \\
0,08 & 0,06 \\
0,08 & 0,05 \\
0,10 & 0,09 \\
0,02 & 0,04 \\
0,09 & 0,11 \\
0,08 & 0,17 \\
0,12 & 0,07 \\
\hline
\end{tabular}




\section{APÊNDICE B}

\section{MICRODUREZA KNOOP}

Tabela 1 - Valores calculados de microdureza knoop.

\begin{tabular}{|c|c|c|}
\hline \multirow[b]{2}{*}{ Resinas } & \multicolumn{2}{|c|}{ Tratamentos } \\
\hline & Sem fibras & Com fibras \\
\hline \multirow{12}{*}{ VIPI WAVE } & 16 & 17,86 \\
\hline & 17,36 & 16,6 \\
\hline & 16,48 & 16,22 \\
\hline & 17,2 & 16,5 \\
\hline & 17,76 & 18,2 \\
\hline & 15,5 & 18,66 \\
\hline & 16,94 & 18,52 \\
\hline & 18,18 & 16 \\
\hline & 16,28 & 17,28 \\
\hline & 16,04 & 16,88 \\
\hline & 15,88 & 17,7 \\
\hline & 15,62 & 16,68 \\
\hline \multirow{15}{*}{ VIPI FLASH } & 15,8 & 15,84 \\
\hline & 15,4 & 15,98 \\
\hline & 15,06 & 15,06 \\
\hline & 15,04 & 15,38 \\
\hline & 15,08 & 16,14 \\
\hline & 15,16 & 15,9 \\
\hline & 14,96 & 15,12 \\
\hline & 15,28 & 16,02 \\
\hline & 15,46 & 14,76 \\
\hline & 15,7 & 15,34 \\
\hline & 15,96 & 15,44 \\
\hline & 15,4 & 15,18 \\
\hline & 16,76 & 18,1 \\
\hline & 18,7 & 18 \\
\hline & 16,68 & 17,62 \\
\hline \multirow{9}{*}{ VIPI CRIL } & 16,08 & 18,12 \\
\hline & 20,02 & 19,28 \\
\hline & 24 & 16,34 \\
\hline & 17,36 & 18,4 \\
\hline & 17,14 & 17,44 \\
\hline & 16,1 & 20,16 \\
\hline & 16,1 & 16,4 \\
\hline & 16,78 & 18,6 \\
\hline & 17,68 & 17,82 \\
\hline
\end{tabular}




\begin{tabular}{|c|c|c|}
\hline & 15,96 & 17 \\
\hline & 16,46 & 16,66 \\
\hline & 16,18 & 17,94 \\
\hline & 15,78 & 16,46 \\
\hline \multirow[t]{12}{*}{ LUCITONE } & 15,6 & 15,9 \\
\hline & 15,8 & 17,28 \\
\hline & 15,42 & 16,44 \\
\hline & 15,46 & 16,08 \\
\hline & 15,62 & 15,94 \\
\hline & 15,54 & 16,52 \\
\hline & 15,36 & 16,72 \\
\hline & 15,56 & 17,34 \\
\hline & 15,7 & 15,88 \\
\hline & 15,52 & 15,9 \\
\hline & 15,52 & 15,8 \\
\hline & 15,5 & 15,62 \\
\hline \multirow[t]{7}{*}{ QC-20 } & 16,1 & 15,94 \\
\hline & 15,7 & 15,88 \\
\hline & 16,72 & 15,52 \\
\hline & 15,72 & 15,4 \\
\hline & 16,92 & 15,36 \\
\hline & 15,6 & 15,48 \\
\hline & 16,12 & 15,4 \\
\hline
\end{tabular}




\section{APÊNDICE C}

\section{MÓDULO DE ELASTICIDADE}

Tabela 1 - Valores calculados do módulo de elasticidade.

\begin{tabular}{|c|c|c|}
\hline \multirow[b]{2}{*}{ Resinas } & \multicolumn{2}{|c|}{ Tratamentos } \\
\hline & Sem fibras & Com fibras \\
\hline \multirow{11}{*}{ VIPI WAVE } & 2242,17 & 3511,42 \\
\hline & 2728,96 & 2915,2 \\
\hline & 1884,55 & 3500,37 \\
\hline & 2417,82 & 3144,57 \\
\hline & 2960,37 & 3341,91 \\
\hline & 2569,48 & 3381,81 \\
\hline & 2599,23 & 3554,09 \\
\hline & 2526,4 & 2978,07 \\
\hline & 2625,63 & 2849,4 \\
\hline & 2156,49 & 3358,27 \\
\hline & 2889,5 & 3162,67 \\
\hline \multirow{15}{*}{ VIPI FLASH } & 2539,67 & 3002,37 \\
\hline & 2717,63 & 3505,11 \\
\hline & 3318,41 & 3879,4 \\
\hline & 3422,39 & 3121,45 \\
\hline & 3017,62 & 3053,26 \\
\hline & 3006,98 & 3541,34 \\
\hline & 2687,95 & 2940,62 \\
\hline & 2911,07 & 3459,85 \\
\hline & 2409,08 & 3588,38 \\
\hline & 2926,65 & 3981,69 \\
\hline & 2893,41 & 3398,27 \\
\hline & 3312,9 & 3477,69 \\
\hline & 2809,05 & 2534,82 \\
\hline & 2624,45 & 4152,22 \\
\hline & 2633,13 & 3470,48 \\
\hline \multirow{9}{*}{ VIPI CRIL } & 2815,39 & 4094,69 \\
\hline & 3027,7 & 3441,92 \\
\hline & 2809,55 & 3434,96 \\
\hline & 2851,82 & 3405,07 \\
\hline & 3126,14 & 4298,39 \\
\hline & 2305,76 & 3509,57 \\
\hline & 2507,54 & 3424,45 \\
\hline & 3209,93 & 3503,26 \\
\hline & 2713,59 & 3833,23 \\
\hline
\end{tabular}




\begin{tabular}{ccc}
\hline & 2322,36 & 3491,81 \\
1937,08 & 3148,43 \\
1860,56 & 3182,85 \\
1906,73 & 2890,27 \\
1918,1 & 2993,1 \\
1936,21 & 3218,8 \\
2028,77 & 2862,38 \\
2037,87 & 3202,97 \\
2040,43 & 3067,65 \\
1952,75 & 3140,24 \\
1475,68 & 2940,76 \\
\hline 1903,16 & 2947,43 \\
1857,07 & 3087,59 \\
2241,39 & 3035,07 \\
1904,21 & 2676,41 \\
1789,05 & 2966,46 \\
2068,93 & 2848,32 \\
2000,44 & 2914,89 \\
& 1795,11 & 2703,85 \\
1833,87 & 2647,3 \\
1798,43 & 2939,66 \\
1741,85 & 2772,9 \\
1880,31 & 3239,74 \\
\hline & & \\
\hline
\end{tabular}




\section{APÊNDICE D}

\section{RESISTÊNCIA FLEXURAL}

Tabela 1 - Valores calculados de resistência flexural

\begin{tabular}{|c|c|c|}
\hline \multirow[b]{2}{*}{ Resinas } & \multicolumn{2}{|c|}{ Tratamentos } \\
\hline & Sem fibras & Com fibras \\
\hline \multirow{12}{*}{ VIPI WAVE } & 82,9 & 101,34 \\
\hline & 90,64 & 83,18 \\
\hline & 73,12 & 91,71 \\
\hline & 72,28 & 96,41 \\
\hline & 85,44 & 80,72 \\
\hline & 93,97 & 93,12 \\
\hline & 89,71 & 103,86 \\
\hline & 92,4 & 84,81 \\
\hline & 82,61 & 83,23 \\
\hline & 69,94 & 86,8 \\
\hline & 93,21 & 86,8 \\
\hline & 76,06 & 75,79 \\
\hline \multirow{11}{*}{ VIPI FLASH } & 85,42 & 92,24 \\
\hline & 82,42 & 87,83 \\
\hline & 87,13 & 82,79 \\
\hline & 79,49 & 78,79 \\
\hline & 87,09 & 88,34 \\
\hline & 76,51 & 82,79 \\
\hline & 83,94 & 80,7 \\
\hline & 77,17 & 84,72 \\
\hline & 74,15 & 90,35 \\
\hline & 75,36 & 82,26 \\
\hline & 84,36 & 82,01 \\
\hline \multirow{13}{*}{ VIPI CRIL } & 86,35 & 74,89 \\
\hline & 63,04 & 99,92 \\
\hline & 63,66 & 95,65 \\
\hline & 62,7 & 94,93 \\
\hline & 71,63 & 92,38 \\
\hline & 63,09 & 71,46 \\
\hline & 68,42 & 93,27 \\
\hline & 67,58 & 115,12 \\
\hline & 54,79 & 89,9 \\
\hline & 59,44 & 88,65 \\
\hline & 73,71 & 87,35 \\
\hline & 63,91 & 94,48 \\
\hline & 58,12 & 97,37 \\
\hline
\end{tabular}




\begin{tabular}{ccc}
\hline & 79,97 & \\
73,96 & 93,74 \\
82,58 & 75,34 \\
83,67 & 84,54 \\
LUCITONE & 70,58 & 88,95 \\
& 83 & 87,72 \\
86,15 & 89,91 \\
59,29 & 91,11 \\
61,83 & 89,69 \\
78,94 & 89,69 \\
& 61,67 & 87,24 \\
& 76,63 & 86,34 \\
\hline 82,38 & 74,95 \\
QC-20 & 75,76 & 79,78 \\
& 85,12 & 91,23 \\
& 79,23 & 88,85 \\
& 71,25 & 96,93 \\
& 70,71 & 56,3 \\
& 54,24 & 63,6 \\
69,32 & 86,18 \\
& 80,26 & 83,64 \\
77,21 & 101,85 \\
87,5 & 79,49 \\
& 77,24 \\
\hline
\end{tabular}

